\title{
AGROECOLOGIA EM TERRAS INDÍGENAS NO BRASIL: UMA REVISÃO BIBLIOGRÁFICA
}

\author{
LUIZ ANTONIO C. NORDER ${ }^{1}$ \\ UFSCAr, BRASIL
}

CARINE ANDRADE TEIXEIRA ${ }^{2}$

UFSCar, BRASIL

RENATA MARIA GUERREIRO FONTOURA COSTA ${ }^{3}$

UFSCar, BRASIL

TATIANE RIBEIRO DOS SANTOS ${ }^{4}$

UFSCAr, BRASIL

ELEN REGINA ROMO TRINDADE 5

UFSCAr, BRASIL

GUSTAVO SCAGLIUSI NOVASKI ${ }^{6}$

UFSCar, BRASIL

GUSTAVO DE ANDRADE POYARES ${ }^{7}$

UFSCAr, BRASIL

MARIO CESAR CADORIN JUNIOR ${ }^{8}$

UFSCAr, BRASIL

MARIA CLEOPHAS FAGGION ALENCAR ${ }^{9}$

EMPBRAPA, BRASIL

\footnotetext{
${ }^{1}$ Professor do Departamento de Desenvolvimento Rural e do Programa de Pós-Graduação em Agroecologia e Desenvolvimento Rural (Universidade Federal de São Carlos, Brasil) E-mail: luiz.norder@gmail.com

2 Discente do Programa de Pós-Graduação em Agroecologia e Desenvolvimento Rural da Universidade Federal de São Carlos (PPGADR/UFSCar). E-mail: carin_andrade@hotmail.com

${ }^{3}$ Discente do Programa de Pós-Graduação em Agroecologia e Desenvolvimento Rural da Universidade Federal de São Carlos (PPGADR/UFSCar). E-mail: remaria.guerreiro@gmail.com

${ }^{4}$ Discente do Programa de Pós-Graduação em Agroecologia e Desenvolvimento Rural da Universidade Federal de São Carlos (PPGADR/UFSCar). E-mail: tatiris@gmail.com

${ }^{5}$ Discente do Bacharelado em Agroecologia da Universidade Federal de São Carlos (UFSCar). E-mail: elen.romo@hotmail.com

${ }^{6}$ Discente do Bacharelado em Agroecologia da Universidade Federal de São Carlos (UFSCar). E-mail: gsnovaski@hotmail.com

${ }^{7}$ Discente do Bacharelado em Agroecologia da Universidade Federal de São Carlos (UFSCar). E-mail: guandradedm@hotmail.com

${ }^{8}$ Discente do Bacharelado em Agroecologia da Universidade Federal de São Carlos (UFSCar). E-mail: cadorinbushi@gmail.com

${ }^{9}$ Pesquisadora da Embrapa Meio Ambiente, Jaguariúna (SP). E-mail: cleofas.alencar@embrapa.br
} 
RESUMO: Este texto apresenta um estudo de revisão bibliográfica sobre as atividades realizadas com base na noção de Agroecologia em terras indígenas de diferentes regiões brasileiras. Foram identificadas 92 publicações que retratam iniciativas e projetos envolvendo diversas terras indígenas, etnias e instituições. Esta produção acadêmica foi analisada a partir de uma classificação em sete temas: práticas agrícolas; agrobiodiversidade; sistemas agroflorestais; manejo florestal e extrativismo; organização social e políticas públicas; educação em Agroecologia em terras indígenas e extensão rural agroecológica e gestão ambiental. Os textos apresentados evidenciam que as atividades inspiradas na noção de Agroecologia têm buscado uma revalorização da identidade, da cultura e das tradições indígenas e, respeitando as especificidades de cada grupo, procuram criar sistemas produtivos sustentáveis e adaptados, bem como promover o manejo florestal sustentável e a formação de sistemas agroflorestais, com a adoção de métodos participativos e dialógicos visando o empoderamento das comunidades, a reflexão sobre as relações de gênero, a juventude, o aprimoramento dos hábitos alimentares e da gestão ambiental e, entre outros aspectos, a reorientação das atividades de ensino e de extensão.

PALAVRAS-CHAVE: Agroecologia; Terras Indigenas; Extensão Rural.

ABSTRACT: This text presents a bibliographic review study about the activities carried out based on the notion of Agroecology in indigenous lands from different Brazilian regions. 92 publications have been identified. It portrays initiatives and projects involving several indigenous lands, ethnicities and institutions. This academic production was analyzed from a classification in seven themes: agricultural practices; agrobiodiversity; agroforestry systems; forest management and extractivism; social organization and public policies; education in Agroecology in indigenous lands and agroecological rural extension and environmental management. The results shows that the set of activities inspired by the notion of Agroecology have sought to revalue indigenous identity, culture and traditions and, respecting the specificities of each group, seek to create sustainable and adapted productive systems, as well as to promote sustainable forest management and the formation of agroforestry systems; it is underlined the adoption of participatory and dialogic methods aimed at the empowerment of communities, the reflection on gender relations, youth, the improvement of eating habits and environmental management and, among other aspects, reorientation of activities in the fields of education and extension.

KEYWORDS: Agroecology; Indigenous Lands; Rural Extension. 


\section{Introdução}

Há no Brasil uma importante tradição de sistematizações bibliográficas e estudos de revisão da literatura sobre as populações indígenas, o que remonta aos três volumes da obra Bibliografia Crítica da Etnologia Brasileira (BALDUS, 1954, 1968; HARTMANN, 1984). Tratase de iniciativas que reúnem, descrevem, analisam e interpretam não apenas publicações científicas sobre as populações indígenas, mas também, em alguns casos, importantes fontes de informações documentais. Ao longo do tempo, estes estudos de sistematização bibliográfica e documental passaram a focar determinadas etnias; entre os exemplos estão Noeli (1998), sobre os Kaingang, e Carvalho et al. (2001), sobre os Aruák no Mato Grosso do Sul e países vizinhos; todavia, os estudos bibliográficos podem também ser voltados para a análise de temáticas específicas em diferentes grupos, como é o caso da bibliografia crítica sobre saúde indígena no Brasil elaborada por Buchillet (2007).

Neste contexto, o objetivo deste artigo é o de identificar, caracterizar e analisar a bibliografia técnico-científica sobre as atividades de ensino, pesquisa e extensão em terras indígenas brasileiras que tenham sido associadas direta e expressamente à noção de Agroecologia. Vale desde já ressaltar que há, seguramente, diversas iniciativas e relatos de atividades similares realizadas em terras indígenas, mas que não foram incluídas neste levantamento em função do critério de seleção escolhido, que pretende abordar, especificamente, as atividades já realizadas em terras indígenas vinculadas de forma expressa e intencional à noção de Agroecologia.

Apesar das diferentes definições e aplicações práticas relacionadas à noção de Agroecologia, há importantes consensos, entre os quais o de uma oposição ao modelo de agricultura fundado na revolução verde e o da utilização de processos naturais e biológicos na produção agropecuária (SARDO; FIGUEIREDO, 2015; BRANDENBURG, 2012). No caso brasileiro, observa-se a predominância da vertente inspirada na economia política ecológica e vinculada ao movimento camponês, tendo em vista que foram justamente as organizações da agricultura familiar as que, a partir da década de 1990, valorizaram e promoveram a Agroecologia como paradigma de desenvolvimento rural sustentável e socialmente justo (CAPORAL; COSTABEBER, 2000). A partir de 2003, houve uma notável adoção desta perspectiva teórica por parte de movimentos sociais, políticas públicas e instituições de pesquisa e ensino (NORDER et al, 2106).

Neste processo, a Agroecologia passou a compor as diretrizes programáticas de políticas públicas para agricultores familiares, populações tradicionais e indígenas, através da Política Nacional de Agroecologia e Produção Orgânica (PNAPO), instituída em agosto de 2012 por meio do Decreto n. 7.794, e da Política Nacional de Gestão Ambiental de Terras Indígenas (PNGATI), instituída em junho do mesmo ano através do Decreto n. 7.747. Entre as principais diretrizes da Agroecologia estão 
a valorização do conhecimento tradicional e o estabelecimento de metodologias participativas e dialógicas com as comunidades. Do ponto de vista técnico, há uma ênfase para uma compatibilização das atividades agropecuárias com as peculiaridades ecológicas e socioculturais de cada região. Nas terras indígenas, as práticas agroecológicas vêm sendo associadas à recuperação de áreas degradadas, à implementação de sistemas agroflorestais e ao extrativismo sustentável.

Tendo em vista este contexto, foi realizado um levantamento bibliográfico sistemático até o ano de 2017 , em diversas bases de dados e plataformas de informação técnico-científica. As principais fontes de informação consultadas foram: Google Acadêmico, SciELO, Base de Dados de Pesquisa Agropecuária (BDPA) da Embrapa, Web of Science e Scopus com as seguintes estratégias de busca: Agroecol* AND Indígena*; Indígena*; Agroecol* indígena*; Terra* indígena* AND (Sistemas florestais OR SAFs). Considerando que várias revistas que tratam do tema aqui estudado não estão indexadas nas principais bases de dados bibliográfica internacionais, também foram utilizados os sites das seguintes revistas especializadas no tema Agroecologia: Revista Agriculturas, Revista Brasileira de Agroecologia e Revista Cadernos de Agroecologia; e, todos anais dos Congressos Brasileiros de Agroecologia.

Para a tipologia livros, foi consultada a base de dados da Biblioteca Nacional já que é a instituição que abriga todas os livros publicados no Brasil para questões de direito autoral. Para recuperar as dissertações e teses produzidas no Brasil, os sites especializados da CAPEs e do IBICT foram consultados e incorporados ao conjunto bibliográfico. Todas as duplicatas foram retiradas. As estratégias utilizadas visaram incluir o maior número possível de publicações para fazer uma análise geral do tema e seu desenvolvimento. Foram identificadas e selecionadas 92 publicações para serem utilizadas como conjunto bibliográfico da pesquisa.

Para organizar esta literatura técnico-científica, o conjunto bibliográfico sobre a temática escolhida foi dividido em sete subtemas, que compõem as seções deste artigo: práticas agrícolas; agrobiodiversidade; sistemas agroflorestais; manejo florestal e extrativismo; organização social e políticas públicas; educação em Agroecologia em terras indígenas e, por fim, extensão rural agroecológica e gestão ambiental. Em vários casos, as publicações abrangem mais de um destes temas, tendo sido, diante disso, realizada uma classificação com base no aspecto considerado predominante.

Esta pesquisa foi realizada como parte de atividade pedagógica voltada para a ampliação do envolvimento com a temática indígena e com a capacitação técnica e científica de estudantes do curso de Bacharelado em Agroecologia e egressos do Mestrado em Agroecologia e Desenvolvimento Rural (PPGADR) da Universidade Federal de São Carlos (UFSCar), que também participam ou participaram de outras atividades de pesquisa e/ou extensão junto às comunidades indígenas. 


\section{Práticas agrícolas}

As práticas agrícolas desenvolvidas pelos indígenas são consideradas não apenas como técnicas de manejo, mas como parte de um modo de vida, de suas tradições, espiritualidade e religiosidade. Os métodos e técnicas utilizados demonstram a relação de respeito com a natureza e evidenciam a importância do conhecimento indígena para a construção da Agroecologia. No entanto, a influência da agricultura convencional, decorrência da aproximação dos povos indígenas com os não índios, provocou o abandono de algumas práticas agrícolas tradicionais.

Um exemplo é analisado por Pinto et. al (2002) na maior aldeia dos índios Bororo, nos municípios de General Carneiro e Barra do Garças (MS); as atividades realizadas pelos indígenas compreendiam coleta, caça, pesca e agricultura e vêm se adaptando às transformações ambientais do cerrado, sendo influenciadas pela exploração agrícola predominante na região. No passado, as atividades agrícolas desenvolvidas pelos Bororo possuíam ligação com os rituais religiosos, principalmente relacionados ao cultivo do milho. Um dos rituais era o Kuiadá Páru, festa do milho, celebrado na colheita. A modernização das atividades agrícolas resultou na dependência de recursos externos e em uma redução na produção de alimentos tradicionalmente consumidos.

Por outro lado, estudos em diferentes regiões e povos indígenas demonstram a permanência de técnicas agrícolas tradicionais e sua importância para o manejo do que conhecemos hoje como agricultura alternativa. Delwing et al. (2006), em pesquisa no Território indígena Yryapu, etnia Mbyá, no município de Palmares (RS), relatam as interações características dos indígenas com o meio ambiente. As práticas agrícolas se caracterizam pela diversidade de cultivares: mandioca, feijão, milho, melancia, entre outros. Nota-se que apenas o milho guarai (avaxi) é uma cultivar tradicional dos Guarani, que possui importância religiosa e social para a comunidade. O plantio é realizado em áreas próximas às moradias, durante o mês de setembro, antes do plantio do milho convencional (juruá). Além das atividades de cultivo, os indígenas atuam na coleta de espécies da mata, para artesanato, para o tratamento de doenças e para a construção de moradias.

A invisibilidade e marginalização da luta indígena pelo direito ao território afeta negativamente os conhecimentos tradicionais, culturais, medicinais e de manejo da terra; outra consequência é a modificação da relação dos indígenas com a natureza. Ao relatar a implementação de um projeto com os Tupinambá de Serra do Padeiro, em Buerarema (BA), Marques et. al., (2007) identificaram práticas agrícolas passadas de geração em geração. Os Tupinambá vinham seguindo o calendário agrícola baseado nas relações com a lua e o sol, que define o momento em que cada cultura deve ser plantada, e quando os tratos culturais devem ser realizados; contudo, este ancestral calendário agrícola vem sendo abandonado no território. 
Em outro levantamento, identificou-se que a forma de plantio utilizada pelos Tupinambá era a coivara, ou agricultura itinerante, que tem como sequência a escolha do terreno, a abertura do terreno com a derrubada e, posteriormente, a queima da mata para o plantio nas cinzas; após o uso, a área é deixada em pousio para o descanso e restabelecimento da fertilidade do solo. Tal prática, assim como o calendário agrícola astrológico, está entrando em desuso, em consequência do contato com a agricultura convencional e da limitação na disponibilidade de terras, o que dificulta a aplicação do pousio e gera impactos na fertilidade do solo. As práticas agrícolas atuais incluem a roçagem, a queimada, o plantio, as capinas e a colheita, com adubação a partir do segundo ano de uso da terra (MARQUES et. al., 2009).

Assim como nos relatos supracitados, a dissertação desenvolvida por Rocha (2010) na Terra Indígena Araçá, habitada por Macuchi e Wapichana, município de Amajari (RR), sobre o Projeto Guyagrofor: Desenvolvimento de Sistemas Agroflorestais Sustentáveis, baseado no conhecimento de populações indígenas e quilombolas no escudo das Guianas, ressaltou a importância do uso da agricultura de corte e queima, influenciada pelo regime sazonal da região, e da alternância entre os períodos de cultivos e pousio. Os principais cultivos na TI Araçá são: mandioca, milho, jerimum, feijão-caupi, cará, batata-doce e pimenta. As roças são cultivadas por famílias, embora existam áreas cultivadas de forma individual; entretanto, o uso do pousio vem se limitando, consequência do aumento da população, da exploração e a limitação das terras.

A impossibilidade do pousio acarretou na redução da fertilidade do solo e, com isso, o cultivo do arroz, que era bastante comum, deixou de ser praticado. De acordo com os indígenas, a terra e a semente estavam "fracas", as capoeiras "cerram" muito e nasce bastante mato, não sendo possível o plantio das cultivares. Também foi relatado o cultivo na caiçara, uma área no Lavrado, cercada, onde o gado é manejado por um período de tempo, seguido do cultivo, preferencialmente, de mandioca e/ou macaxeira e banana. Nos quintais, há a criação de galinhas e porcos, 0 que está associado à escassez da caça.

A mata tem sido apontada como imprescindível para as tradições culturais, sociais e religiosas dos indígenas. Para os povos Ticuna e Cocama localizados no município de Benjamin Constant (AM), o uso dos recursos naturais relaciona-se com a religiosidade - e a preservação da mata permite a formação do composto orgânico ngauraou 'paú', resultado da maceração de folhas e galhos secos, utilizado nos roçados para aumentar a produtividade do solo (NODA et al., 2012). Em outro trabalho com os Ticuna e Cocama, Noda et al. (2008) levantaram informações sobre o sistema de plantio margeado por mata virgem ou capoeira, com objetivo de proteger as plantas do excesso de chuvas e ventos, o que também contribui para a regeneração das áreas derrubadas para os plantios. O pousio possui o tempo médio de quatro anos, havendo a possibilidade de realizar o plantio de frutíferas perenes para constituir novos sítios. 
As técnicas de baixo impacto evidenciam como os indígenas consideram o solo fundamental para a produção de alimentos. Ramos et al. (2013) analisam a relação de respeito à terra entre os Tapirapé da aldeia Tapi'itãwa, localizada na Terra Indígena Urubu Branco, no município de Confresa (MT). A escolha da área para o plantio é responsabilidade dos mais velhos, tendo em vista os conhecimentos adquiridos ao longo da vida. A prática do pousio é utilizada para o restabelecimento da vegetação - e o formato das roças tem suas peculiaridades, podendo ser retangular ou circular, para que as plantas fiquem de pé ao redor da roça, ou seja, atuando como uma barreira viva protegendo a lavoura de ventos, do ataque de pragas e da radiação solar. O plantio é feito em consorcio, pois acreditam que a coexistência das plantas gera um efeito benéfico. Nas áreas próximas às moradias (quintais), é encontrada uma diversidade de plantas que permite caracterizar estas áreas como sistemas agroflorestais.

Assim como em outros relatos, os Borari da Aldeia Novo Lugar, TI Maró, em Santarém (PA), realizam o corte e queima chamado de coivara. Cada família é responsável pelo seu roçado, mas algumas atividades são executadas de forma coletiva, conhecida como puxurum, praticada em forma de rodízio pelas famílias, para colaborar com a preparação e implantação dos roçados. A área dos Borari é utilizada em atividades agrícolas e extrativistas; para o plantio são destinadas as áreas na colônia, localizadas distantes do rio, nas quais são plantadas mandioca e outros gêneros alimentícios. As tarefas são divididas por sexo: os homens trabalham com a terra e as mulheres com o preparo dos alimentos; no dia a dia, é responsabilidade das mulheres cuidar da casa, dos quintais, dos animais, do plantio e da colheita, enquanto aos homens cabem as atividades de derrubada da mata e preparação do terreno, pesca, caça e coleta de recursos naturais (FERREIRA; SABLAYROLLES, 2014).

A influência do contato com os não indígenas alterou o modo de vida indígena, interferindo nos sistemas tradicionais de produção. Iniciativas como a desenvolvida na comunidade indígena Monte Cristo, etnia Tukano, no município de São Gabriel da Cachoeira (AM), no período de novembro de 2009 a agosto de 2010, para a implantação de hortos caseiros mistos ou quintais agroflorestais, contribuíram para reconectar os indígenas com as suas tradições, muitas vezes perdidas, e os resultados apresentados apontam para uma boa aceitação dos sistemas agroflorestais por parte da comunidade (GUIMARÃES, et al., 2011).

Os diferentes relatos apresentados sobre as atividades agrícolas indígenas possibilitam perceber a relação de respeito com o uso e preservação do solo. A agricultura itinerante ou coivara é uma prática comum entre diferentes povos e regiões. A aproximação com os não indígenas e a limitação de área estão acarretando no desaparecimento de conhecimentos, técnicas de manejo e cultivares ancestrais, colocando em risco suas atividades tradicionais voltadas para a construção da segurança alimentar. As práticas indígenas tradicionais passam a ser valorizadas e articuladas com inovações sustentáveis, em geral, no âmbito de ações de extensão orientadas pela noção de Agroecologia. 


\section{Agrobiodiversidade}

A agrobiodiversidade, entendida como a riqueza de variedades e espécies agrícolas relacionadas ao conhecimento local e própria de uma determinada comunidade humana, seja ela rural, tradicional ou indígena, vem ganhando espaço como um importante componente para a conservação dos mais diversos agroecossistemas e biomas por todo o mundo. No Brasil, relevantes pesquisas relacionadas ao tema evidenciam a contribuição dos povos indígenas para alcançar este objetivo. Nesta revisão bibliográfica, destacam-se os seguintes eixos: resgate cultural da agrobiodiversidade, manejo da agrobiodiversidade e de sementes tradicionais e crioulas, criação de casas de sementes, organização de feiras de sementes e mudas e oferta de cursos de formação.

Em relação ao manejo da agrobiodiversidade, importante trabalho foi feito por Kaiabi et al. (2004). Entre 1998 e 2004, indígenas Kaiabi e Yudja, em parceria com o Instituto Socioambiental (ISA), se organizaram com o intuito de promover a revitalização dos sistemas de manejo da agrobiodiversidade no Parque Indígena do Xingu (MT). Foi com isso possível resgatar e fortalecer as práticas de manejo da agrobiodiversidade vinculadas às suas etnias, através do estudo das variedades genéticas, da multiplicação de germoplasmas e da realização de cursos e capacitações; no entanto, os desafios presentes estão relacionados, entre outros fatores, às transformações na transmissão dos conhecimentos e às diferentes percepções relacionadas ao uso sustentável dos recursos naturais. Os indígenas têm buscado uma revalorização dos conhecimentos, manejos e usos tradicionais da agrobiodiversidade. Para isso, povos do Xingu vêm participando ativamente na formulação e gestão de políticas públicas e para o reconhecimento dos direitos intelectuais coletivos dos indígenas.

No estado do Amazonas, foram levantadas informações a respeito da agricultura de corte e de queima em quatro comunidades pluriétnicas: Barreirinhas, Boa Esperança, Nova Esperança e Coanã (etnias Baré, Cubeo, Piratapuia, Tukano, Tikuna e Sateré-Mawé) a $50 \mathrm{~km}$ de Manaus, no baixo rio Negro, com destaque para 0 manejo e conservação da agrobiodiversidade local e regional (CARDOSO, 2009). O estudo mostrou a importância desse sistema de produção agrícola para os povos indígenas, pautado nas seguintes fases: escolha da área, derrubada e queimada, plantio e abandono, configurando-se um mosaico na paisagem com distintas fases sucessionais da flora. A partir dessa prática, as etnias envolvidas mantiveram seus conhecimentos sobre o manejo da agrobiodiversidade amazônica e promoveram sua segurança alimentar através da seleção e propagação de espécies essenciais para a manutenção dos seus modos de vida, com enfoque para a mandioca nos roçados, em um total de 70 etnovariedades de mandioca e outras 54 etnoespécies.

Há alguns importantes estudos sobre o conhecimento indígena tradicional relacionados à agrobiodiversidade. Heckler (2006), com base em pesquisa etnográfica, analisou as relações dos Mbyá-Guarani, 
particularmente das aldeias de Itapuã (RS) e Piraquara (PR), com as sementes de milho, com enfoque no potencial educativo das sementes. Os Guarani detêm um grande conhecimento sobre a agrobiodiversidade, principalmente relacionado às variedades tradicionais de milho, que, entre outros aspectos, relacionam-se à sua religiosidade. Trocas de sementes tradicionais têm sido organizadas sistemática e periodicamente por indígenas e não-indígenas na região sul do país, o que tem possibilitado a formação de uma rede agroecológica regional.

No mesmo sentido, um diagnóstico da agrobiodiversidade presente em áreas indígenas Guarani Nhadewa no norte do Paraná, com enfoque no conhecimento dos anciões, foi realizado por Almeida (2012). O conhecimento sobre a agrobiodiversidade da cultura Guarani está presente na memória dos indígenas, e existe o interesse para que essas sementes e outras variedades crioulas sejam resgatadas. No entanto, apesar de algumas iniciativas recentes, muitas dificuldades foram encontradas, como a falta de apoio governamental local e o desinteresse dos jovens por tais ações. Apesar de escassa, na atualidade, há a presença de variedades de sementes tradicionais nas comunidades estudadas e a pesquisa possibilitou suscitar uma reflexão juntamente com os Guarani Nhandewa sobre a situação atual das práticas agrícolas tradicionais e sobre o conhecimento associado a elas. Além disso, ressalta-se que, em poucas décadas, houve uma grande transformação na forma de viver dos indígenas, associada, principalmente, à adoção da agricultura moderna em detrimento das práticas agrícolas tradicionais.

Os esforços que os povos indígenas têm feito para que as sementes tradicionais ou crioulas sejam conservadas, manejadas e trocadas com diversos grupos, em distintas regiões do país, foram pesquisadas por alguns autores. Na TI Guarita (RS), habitada pelos Kaingang e Guarani, foram realizadas entrevistas, no primeiro semestre de 2012 , com os guardiões indígenas de sementes crioulas, com o propósito de investigar as paisagens manejadas onde são cultivadas as variedades tradicionais (FEIJÓ et al., 2013; FEIJÓ, ANTUNES, PEREIRA, 2014). Foram identificadas diversas espécies crioulas que vêm sendo preservadas há muitas gerações, principalmente algumas variedades de feijão e milho, cultivadas nas bordas de planalto (de 300 a 420m), onde encontram-se capoeiras e matas nativas. O interesse em manter e diversificar as sementes crioulas na TI Guarita está presente em muitos indígenas; no entanto, alguns desafios são apontados, como o de ampliar o interesse dos jovens. A criação de projetos de extensão universitária, políticas públicas e de projetos de pesquisa locais que estimulem estas práticas são estratégias que podem possibilitar o fortalecimento dessas iniciativas.

Dias et al. (2014) e Santos (2014) retratam, de forma abrangente, o percurso do povo Krahô, da TI Krahôlandia (TO), para resgatar variedades de sementes tradicionais a partir da década de 1990, com o apoio da Fundação Nacional do Índio (Funai), em parceria com a Empresa Brasileira de Pesquisa Agropecuária (Embrapa). Desde então, os Krahô se fortaleceram através do incremento de suas roças tradicionais, firmaram acordo de cooperação técnica com a Embrapa e realizam as feiras Krahô 
de sementes tradicionais. O grupo incentivou outros povos indígenas a organizar suas próprias feiras de sementes tradicionais e a buscar o resgate de suas variedades. Assim, restabeleceram parte de seu roçado tradicional e tornaram-se referência de trabalho em prol da conservação da agrobiodiversidade indígena.

No tocante à conservação da agrobiodiversidade, foram sistematizadas informações, no período de 1990 a 2015, a respeito do trabalho que a Embrapa tem feito em conjunto com os povos indígenas para a conservação da agrobiodiversidade, pautada na conservação in situ/on farm nas roças indígenas e na conservação ex situ realizado pela Embrapa (DIAS et al., 2015). Foram relatadas experiências realizadas com cinco etnias (Krahô, Paresi, Kaxinawá, Kaingang e Guarani Mbyá) e com povos do Parque Indígena do Xingu. Os indígenas têm alcançado êxito na recuperação de variedades agrícolas tradicionais e vêm diversificando as estratégias para a conservação da agrobiodiversidade. Houve um avanço no sentido de estreitar laços entre e a Embrapa e as comunidades indígenas para a conservação das variedades agrícolas tradicionais, o que se expressa em iniciativas criativas em diversas regiões do país.

Parcerias como estas, inspiradas na noção de Agroecologia, têm se revelado de grande relevância para a conservação da agrobiodiversidade e se manifestam, concretamente, em diferentes ações específicas. Dias et al. (2014a) analisam os cursos realizados por duas unidades da Embrapa (Recursos Genéticos e Biotenologia; Hortaliças) situadas no Distrito Federal, para indígenas de quatro etnias, com a colaboração da Funai, nos quais os grupos conheceram a Coleção de Base de Germoplasma e as coleções de hortaliças tradicionais.

Os cursos objetivaram promover a troca de conhecimentos sobre a agrobiodiversidade entre a Embrapa e os indígenas, e também disponibilizar variedades agrícolas que já não vinham sendo facilmente encontradas em seus territórios. Os Kayapó, após verem os bons resultados do trabalho pioneiro da instituição, em parceria com os Krahô, realizaram sua primeira feira de sementes tradicionais em 2012. Por meio dos cursos realizados, os indígenas das etnias Krahô, Canela, Apinajé, Kayapo puderam conhecer novas técnicas agroecológicas de plantio de diversas culturas, receberam muitas sementes e mudas de interesse particular de cada cultura e fortaleceram e incrementaram suas práticas agrícolas tradicionais.

De forma a caracterizar as feiras de sementes tradicionais realizadas pelos povos indígenas, também em parceria com a Embrapa, Dias et al. (2015a) identificaram as principais atividades realizadas de 1997 a 2015 , e apresentam reflexões sobre seus desdobramentos. Foram até então realizadas nove feiras de sementes, envolvendo as etnias Krahô, Xerente, Paresi, povos de Roraima e do Médio Purus, o que resultou no fortalecimento das práticas agrícolas tradicionais e na articulação de políticas públicas que contemplam este objetivo, com destaque para o Plano Nacional de Agroecologia e Produção Orgânica (Planaplo). A conservação da agrobiodiversidade através da promoção de feiras de sementes tradicionais indígenas tem se mostrado eficaz e contribuído para a segurança alimentar dos povos indígenas brasileiros. 
Durante a realização da IX Feira Krahô de Sementes Tradicionais, entre 16 e 17 de outubro de 2013, na TI Krahôlandia (TO), foi realizado um levantamento sistemático do número de participantes, das espécies e variedades ofertadas para a troca e demais informações acerca do evento (MORAES et al., 2014). Foram registradas 108 variedades agrícolas, com destaque para as de fava, feijão, milho, arroz e gergelim. Compareceram ao evento cerca de 2.000 pessoas, entre indígenas e não-indígenas, com a participação de representantes de 19 etnias. A feira, na sua nona edição, vem se consolidando como uma exitosa iniciativa relacionada à prática de conservação da agrobiodiversidade indígena, possibilitando a troca de conhecimentos sobre as práticas tradicionais agrícolas entre diversos povos indígenas e parceiros - e tem motivado outras etnias a promoverem eventos semelhantes em suas aldeias.

Há uma diversidade de estratégias locais específicas voltadas para a recuperação e revalorização das sementes tradicionais. O trabalho de Ballivián, Ventura e Oliveira (2007) aborda uma iniciativa realizada por uma família Kaingang na TI Guarita (RS), no âmbito da qual foi construída uma casa de sementes no setor Três Soitas, com o objetivo de incentivar a comunidade a plantar sementes crioulas e promover trocas de germoplasma intra e inter-aldeã, frente ao domínio do agronegócio na região. A iniciativa inspirou indígenas da aldeia vizinha, Setor Pedra Lisa, a replicar a experiência, entendida como uma estratégia local para o fortalecimento de práticas agrícolas tradicionais.

Diante das experiências relatadas, envolvendo povos indígenas e instituições diversas, verificam-se ações realizadas em diferentes regiões do país visando a conservação da agrobiodiversidade e para a implementação de políticas públicas, projetos e programas com este propósito. No entanto, ressalta-se a necessidade de maiores investimentos, governamentais e de outras fontes, que possam colaborar para a realização de pesquisas e atividades de extensão nesta área, envolvendo aspectos da agrobiodiversidade e da Agroecologia - e desta forma promover o (re)envolvimento e as práticas dos povos originários voltados para a manutenção dos agroecossistemas e para o incremento da (agro)biodiversidade.

\section{Sistemas agroflorestais (SAFs)}

Os Sistemas Agroflorestais (SAFs), entendidos como um consórcio de espécies arbóreas com culturas agrícolas, com a finalidade de recuperação ou de produção, incluem métodos e técnicas aplicados tradicionalmente na cultura indígena brasileira, e representam atualmente uma alternativa econômica e sustentável à agricultura convencional. Estudos realizadas em todo o território nacional evidenciam que muitas das comunidades Indígenas passaram por uma desestruturação de seu sistema de cultivo tradicional em meio à expansão da agricultura convencional e da pecuária extensiva; por outro lado, há o registro de que, em diversas regiões do país, houve a aplicação de conceitos agroflorestais em novas bases, seja para o fortalecimento da 
autonomia alimentar, para a revalorização da cultura tradicional e para a conservação da biodiversidade.

Assim, iniciativas agroflorestais realizadas em comunidades foram realizadas com base em parceria com a UFAM (Universidade Federal do Amazonas) e o IFAM (Instituto Federal do Amazonas) no estado do Amazonas, mais especificamente nas Tls Lago de Araras, município de Caapiranga e Assunção do Içana, Região do Alto Rio Negro (AM). Castro (2007) e Pinto (2009) destacam a importância dos SAFs, também denominados quintais agroflorestais, quando no entorno imediato das residências, no desenvolvimento sustentável dessas comunidades e na construção de práticas produtivas com menor dependência em relação aos insumos industrializados, o que também contribui para o equilíbrio dos ecossistemas, para a segurança alimentar e para a manutenção da biodiversidade regional. Este último aspecto vem sendo apontado por Pinto (2009), no qual foi analisada a composição florística destes quintais. Enfatiza-se amplamente a eficiência de tais práticas de cultivo sustentável no ambiente amazônico.

Em Roraima, foi apresentada por Pinho (2008) uma dissertação de mestrado em Ciências Florestais Tropicais (UFAM) na qual demonstra-se a eficiência dos Sistemas Agroflorestais em Bioma de Savanas, especialmente em áreas de lavrado, na Terra Indígena Araçá, Wapichana e Macuxi, no município de Amajari (RR), não só para a sustentabilidade da comunidade, mas também para a melhoria na qualidade do solo. Apesar da predominância de espécies exóticas, gerou-se uma notável abundância em frutos nativos muito utilizados na alimentação das comunidades locais.

Vários estudos e pesquisas vêm sendo realizados sobre as características de sistemas agroflorestais tradicionais e recentes. Um deles foi apresentado como tese de doutorado em 2014 na Universidade de Córdoba (Espanha) sobre sistemas agroflorestais apícolas (Wolff, 2014; Wolff et al., 2015). As pesquisas foram realizadas em quatro localidades, uma delas em território indígena Guarani, no Rio Grande do Sul, visando analisar a eficiência dos diversos estilos de manejo apícola agroflorestal com abelhas melíferas africanizadas e nativas sem ferrão. A pesquisa mostra que existe uma grande adaptabilidade dos sistemas apícolas ao seu entorno agroflorestal e ressalta a importância do conhecimento floral e apícola das comunidades tradicionais nesse processo.

Ainda sobre o desenvolvimento da meliponicultura em sistemas agroflorestais, Fernandes, Silva e Macedo (2009) realizaram, como parte do Projeto de Educação Agroflorestal da Escola Indígena Maadzero, atividades interativas com o objetivo de implantar a meliponicultura nos SAFs dos Baniwa da Terra Indígena Tunuí Cachoeira, em São Gabriel da Cachoeira (AM), por meio da promoção de oficinas, intercâmbios e entrevistas visando agregar o conhecimento da biodiversidade e técnicas locais na implantação das caixas. De acordo com os autores, a prática 
contribuiu para a segurança alimentar e para a ampliação do conhecimento técnico dos indígenas.

As metodologias participativas e dialógicas também foram utilizadas em ações de resgate de saberes agroflorestais, um deles no Tocantins, com indígenas da etnia Krahô. O objetivo da atividade era o de reverter a desestruturação dos métodos tradicionais de cultivo e incentivar a utilização de princípios e técnicas agroecológicas, considerados como parte de um processo lento e gradual e que precisa ser realizado a partir das crenças religiosas e culturais da etnia, como citado por Bueno, Armando e Sugasti (2007).

O uso da comunicação como ferramenta de extensão foi a premissa de trabalhos vinculados ao Projeto GATI pela implementação da PNGATI (Política Nacional de Gestão Ambiental e Territorial Indígena), conquista das lideranças indígenas na Eco 92, política esta que visa fortalecer e valorizar as práticas sustentáveis de produção de alimento, reflorestamento e valorização da cultura e modo de vida indígena. No Mato Grosso do Sul, foi realizado uma troca de saberes agroflorestais com Indígenas de etnia Terena e Guarani/Kaiowá na Terra Indígena Sassoró (Duarte, Martins e Aguilar, 2014). Também Souza e Salvador (2014) ressaltam a importância das práticas agroflorestais como alternativa à agricultura convencional extensiva, para a consolidação da segurança alimentar, revalorização cultural e socioeconômica e para a preservação dos sistemas naturais na Aldeia Lalima (Terena) no município de Miranda (MS).

A implementação de SAFs demonstrativos como ferramenta de extensão é analisada em estudo no bioma de Savanas, no estado de Roraima, abrangendo as Tls Amajari, Alto São Marcos e Taiano, fortemente impactadas pela agricultura convencional. Neves e Morais (2015) relatam os resultados de projeto de extensão conduzido pelo Instituto Federal de Roraima (IFRR) que visou a instalação de um SAF em áreas de ilhas de mata, com a finalidade de favorecer a soberania alimentar dos indígenas e priorizar os conhecimentos tradicionais dos alunos indígenas participantes.

Há também o relato sobre a formação de um quintal agroflorestal na Aldeia de Panambizinho (MS), uma área do casal Saliete e Lindomar, da etnia Guarani/Kaiowá, como alternativa ao plantio em monocultivo. Alves e Dias (2014) enfatizam que, inicialmente, foi inserido o adubo verde visando a recomposição da qualidade do solo e microclima propício aos indivíduos que se localizavam na sombra do feijão guandu, facilitando a inserção das espécies arbóreas a serem futuramente utilizadas como fonte de alimento e renda.

Os SAFs podem ainda buscar, simultaneamente, o fortalecimento cultural, a segurança alimentar e a conservação da biodiversidade, como foi o caso do projeto de extensão realizado por equipe da Universidade Estadual de Londrina (UEL) na TI Apucaraninha, em Tamarana (PR), junto à etnia Kaingang. Foi implementado um SAF interligando dois fragmentos florestais e realizados plantios de mudas de araucárias nos fragmentos, 
em um contexto histórico de ampla destruição florestal. Norder e Rodrigues (2007) e Rodrigues (2008) relatam as atividades de plantio de mudas, os problemas gerados pelo uso descontrolado do fogo em uma paisagem que, devido à degradação, vinha sendo dominada pelo capim braquiária, introduzido anteriormente por ações colonizadoras, e apontam para a importância de atividades e de materiais didáticosculturais focados em situações específicas.

A valorização da cultura indígena ancestral é um importante pressuposto para a realização de ações de extensão agroecológica e um dos formatos adotados é o das oficinas. Bianchini (2006), em dissertação de mestrado, e Bianchini e Bianchini (2007) concluíram que a implementação de SAFs e a promoção de oficinas em terras indígenas do estado do Acre, focando principalmente a formação dos AAFIs (Agentes Agroflorestais Indígenas) como agentes de mudança na própria comunidade com a perspectiva de conciliar os saberes tradicionais indígenas com as práticas agroflorestais.

Este conjunto de publicações demonstra que os sistemas agroflorestais em terras indígenas no Brasil representam uma contraposição aos impactos sociais e ambientais da agricultura convencional, bastante intensos especialmente na região sul do país, e estão articulados com as iniciativas de revalorização da cultura, da segurança alimentar e de preservação da biodiversidade. Estas iniciativas, em geral promovidas por instituições de ensino e pesquisa, apontam ainda para sua relação com outros temas relevantes, como a meliponicultura, a participação dos jovens, o envolvimento das escolas nas aldeias e a importância das políticas públicas e ações de extensão rural agroecológica.

\section{Manejo florestal e extrativismo}

Diante da intensa relação que os povos indígenas estabelecem com os ambientes naturais através de práticas extrativistas (de flora e de fauna) e de manejo (conservação e uso sustentável de seus recursos), de acordo com as diversas fitofisionomias florestais, são gerados ricos e diversos contextos socioculturais e que precisam ser pautados e estudados a fim de se estabelecer novas formas e olhares ao se tratar desses recursos naturais e culturais.

As publicações analisadas nesta seção tematizam a valorização dessas técnicas tradicionais e as articulam com novos conhecimentos técnico-científicos, trabalhados por diversos grupos de pesquisa e extensão, e que gerou significativas interações entre os saberes indígenas e não-indígenas. É possível encontrar diversos modelos de manejo florestal e de extrativismo, entre os quais: a disseminação e o fortalecimento de manejos tradicionais em diferentes biomas, a recriação de métodos comunitários de organização, a extração de recursos florestais (como, por exemplo, os subprodutos de abelhas nativas) 
através de análises histórico-sócio-culturais e ambientais, havendo também um enfoque sobre o aspecto econômico da conservação e uso dos recursos naturais.

Com a finalidade de garantir o sucesso dos diversos produtos oriundos de espécies florestais utilizadas pelos indígenas, o manejo de polinizadores tem sido recorrente, pois é possível extrair diversos produtos e subprodutos das abelhas nativas, além da garantia da polinização de espécies florestais que serão utilizadas posteriormente. Isso é demonstrado no trabalho realizado entre 2003 e 2008 por pesquisadores do Instituto Natureza, Gente e Arte (INAGEA/Bahia), a Empresa Baiana de Desenvolvimento Agrícola (EBDA), a Universidade Federal de Feira de Santana (UEFS) e a Universidade de Brasília (UnB). A iniciativa teve como objetivo a criação e o manejo sustentável de abelhas sem ferrão no Território Indígena Pankararé, situado na caatinga baiana. O manejo adotado pelo projeto, contribuiu para conservar e utilizar os recursos da região e gerar novas fontes de renda para as comunidades, aumentando significativamente o número de meliponicultores, devido principalmente às oficinas realizadas (Nunes, 2009).

Nesta mesma TI, há importante atuação do Núcleo Iraí de Desenvolvimento Sustentável (NIDS) da Universidade de Brasília (UnB). Barreto e Castro (2007) demonstram a importância da polinização cruzada da espécie do umbuzeiro (Spondias tuberosa) pelos agentes polinizadores locais, como abelhas, vespas, formigas e moscas. Além da produção sustentável da meliponicultura, sugeriram a redução de caça de animais silvestres dispersores de sementes. O grupo foi responsável também pela construção de um viveiro de mudas e por ações de extensão com o objetivo de promover um enriquecimento de espécies forrageiras na área.

Modercin, Castro e Bandeira (2007), também na TI de Pankararé, propuseram a construção de um diálogo entre a comunidade indígena e a científica, a fim de descrever as atividades realizadas na comunidade. Um dos objetivos foi propagar a produção de meliponicultura, já que, como relatado pelos meleiros indígenas, o número de abelhas vinha sendo reduzido nos últimos anos. Por meio de oficinas, também como parte das atividades do NID/UnB, foram trabalhadas a construção de diversos modelos de caixas adaptadas para a criação de diferentes espécies de abelhas, além da construção de um pequeno galpão para armazenamento das caixas.

As comunidades indígenas, já conhecidas pelas práticas de conservação da biodiversidade, demonstram uma notável capacidade de restauração de ambientes florestais submetidos historicamente aos processos de devastação. Maciel (2012), ao analisar a experiência dos Guarani Nhandewa no norte do Paraná, identificou aspectos socioculturais, econômicos, históricos e ambientais relacionadas à recuperação de florestas em áreas degradadas na TI Laranjinha, em Santa Amélia (PR). A restauração florestal foi realizada com base no manejo altamente eficiente de sistemas agrossilvipastoris de baixa intensidade 
animal, por meio de intervenções planejadas e organizadas pela própria comunidade, praticamente sem qualquer acompanhamento técnico especializado. O resultado, bastante positivo, foi o de ultrapassar em dez vezes a área florestada num período de 15 anos, que recebeu apenas um incentivo indireto através do ICMS Ecológico, política pública estadual que auxiliou a fortalecer as antigas tradições etnobotânicas daquela comunidade. A comunidade demonstrou, portanto, expressiva habilidade em promover, de forma autônoma, uma ampla restauração florestal no interior de seu território.

Por outro lado, em alguns casos, há uma intensificação no consumo e, principalmente, na comercialização de certos produtos de origem florestal, o que pode demandar maior atenção em termos de avaliação e planejamento. No estado do Amapá, Queiroz, Santos e Nóbrega (2015) promoveram, no período de 2012 a 2014, o intercâmbio de conhecimentos técnico-científicos com os conhecimentos indígenas. Os povos indígenas do Oiapoque, que possuem quatro etnias Karipuna, Palikur Galibi e Galibi Kali'na, estão distribuídos em três terras indígenas contínuas, Uaçá, Galibi e Juminã. O projeto, desenvolvido em uma parceria envolvendo Instituto Estadual de Florestas do Amapá (IEF), Instituto de Desenvolvimento Rural do Amapá (Rurap), a Fundação Nacional do Índio (Funai) e a ONG Indigenista lepé, favoreceu o aumento do número de açaizeiros, minimizando os impactos nas florestas.

Graças às trocas de conhecimentos entre pesquisadores e indígenas, foram adaptados tecnologias e conhecimentos tradicionais no manejo de açaizeiros em parcelas demonstrativas instaladas próximas a BR-1 56, na TI Oiapoque/AP. Foi adotado o Manejo de Mínimo Impacto, na qual foi recomendado que o açaizal seja conduzido para uma densidade de 400 touceiras de açaí/ha e cada touceira com cinco estipes adultos (com frutos), quatro estipes jovens e três perfilhos, totalizando um total de 4.800 estipes/ha, com altura máxima de 14 metros. Com isso, esperava-se encontrar como resultados o menor esforço e mais segurança na coleta dos cachos de açaí, aumento na produção de seus frutos, ampliação do período de coleta e os frutos sendo coletados nos estágios ideais de maturação.

De maneira semelhante, no município de Andirá-Barreirinha, no estado do Amazonas, Silva, Lourenço e Xisto (2011) avaliaram, com base em métodos participativos, alguns indicadores de sustentabilidade no manejo de agroecossistemas de guaraná, junto a três famílias da Terra Indígena Sateré Mawé. Foi demonstrado que nestas áreas foram encontrados altos índices de sustentabilidade no manejo que vinha sendo realizado e que o guaraná tem grande importância para as famílias, já que é uma de suas principais fontes de renda.

Entre os Apurinã, localizados no município de Boca do Acre (AM), buscou-se uma ampliação da sustentabilidade no manejo da tucumã (Astrocaryum aculeatum), utilizada na confecção de artesanato em um contexto no qual a comunidade vem manifestando a intenção de manter diversas práticas culturais, incluindo o uso dessa espécie. Foi organizada 
uma oficina sobre artesanato pela ONG Pesacre (Grupo de Pesquisa em Sistemas Agroflorestais do Acre) para viabilizar a transmissão do uso da tucumã para as próximas gerações, tendo sido criada uma associação autogestionada pelos indígenas para impulsionar a geração de renda. Foi registrada uma redução do êxodo na comunidade, assim como uma ampliação da capacidade de conservação dos recursos naturais. A ampliação na renda da comunidade repercutiu na melhoria das habitações, em vacinas para animais e aquisição de filtros d'água, entre outros aspectos. Apesar da pressão dos fazendeiros do entorno, houve uma retomada na luta pela terra e pela conservação de sua cultura, assim como a conservação da floresta, através de práticas como a de coletar as sementes de tucumã somente após os animais silvestres terem se alimentado delas, assegurando sua dispersão (CANISO, 2006).

Parte das atividades de pesquisa e publicações vêm sendo realizadas por autores indígenas, como é o caso de Kayapó (2013), que buscou apoio em instituições para atuar nas TIs Kayapó A'Ukre, Moikarakô e Kikretum, no sul do estado do Pará. Seu foco foi desenvolver e aprimorar a extração, o armazenamento e o escoamento sustentável de castanha. Houve ganho de eficiência nas condições de comercialização do produto. A iniciativa obteve êxito no acesso às políticas de preço mínimo, em parceria com o governo federal, o que aumentou a geração de renda da comunidade e valorizou a cultura tradicional dessas comunidades.

As publicações aqui analisadas apontam para a forte associação entre a perda da biodiversidade e o abandono das tradições culturais, uma vez que estas tecnologias e técnicas haviam sido adaptadas às mais diversas condições de solo, clima, disponibilidade de espécies vegetais e animais e às condições fisionômicas dos territórios. Além disso, houve uma substancial redução na disponibilidade de recursos naturais que vinham sendo utilizadas nas mais diversas atividades dos indígenas. A limitação ou a ausência de políticas públicas adequadas dificulta a reafirmação e revalorização do conhecimento e da sabedoria dos povos indígenas. Apesar de todos esses desafios, os povos indígenas continuam mantendo a notável capacidade para a elaboração de estratégias e práticas a fim de restabelecer e fortalecer o uso das técnicas de manejo, do extrativismo sustentável e do processamento de produtos oriundos das florestas nativas, sejam elas primárias ou restauradas.

\section{Organização social e políticas públicas}

A organização social dos povos originários no Brasil é bastante diversificada, e apresenta particularidades socioculturais e trajetórias históricas específicas; além disso, estão em um multifacetado e heterogêneo intercâmbio com outras etnias e com diversos atores e instituições sociais. As ações identificadas com a Agroecologia estão associadas, de uma forma geral, à promoção social indígena, à soberania alimentar e ao bem viver. As experiências de organização social e de 
políticas públicas aqui analisadas foram realizadas entre 2007 e 2016 , e abrangem temas como gênero, economia solidária, lutas agrárias, migrações, soberania alimentar, políticas públicas, educação, intercâmbios étnicos e culturais, inovação e transformação técnica e tecnológica, promoção social e resgate cultural, cosmovisões e trajetórias históricas dos povos.

Neste contexto, há vários relatos sobre os intercâmbios e encontros que de várias maneiras fomentaram o bem viver dos povos, através das trocas de sementes, bem como de experiências, saberes e culturas. Em abril de 2015, a $2^{\text {a }}$ Caravana Agroecológica, promovida e financiada por diversas instituições, não apenas governamentais, possibilitou que estudantes, técnicos, professores e agricultores visitassem a Aldeia Guarani Boa Esperança, em Aracruz (ES). O cacique narrou aos visitantes o processo histórico da aldeia, marcado pela intensa história de luta contra o latifúndio da indústria celulósica, ocasião em que também tiveram contato com as danças tradicionais. Ferreira, Ferraz e Barbosa (2015) analisaram a importância destas atividades em termos educativos e de conscientização social.

De forma semelhante, no ano seguinte, uma visita ecológica guiada foi realizada com estudantes da Universidade Federal Rural do Semi-Árido (UFERSA) à comunidade Jenipapo Kanindé, no município de Aquiraz (CE). Foram apresentadas as tecnologias sociais existentes e os visitantes acompanharam, por meio das explicações do cacique e de outros residentes do local, a transição da roça de queimada para os sistemas agroflorestais, bem como da história de luta pela preservação ambiental de uma duna nos arredores. A atividade foi considerada muito relevante tanto pelos indígenas quanto pelos estudantes (Viana, 2016).

Em uma outra modalidade de intercâmbio, estudantes indígenas das etnias Amanayé, Atikum, Assuriní, Suruí-Aikewara, Akrãtikatêjê, Parkatêjê e Guajajara, no último ano do curso técnico em Agroecologia do Instituto Federal do Pará (IFPA), em Marabá (PA), participaram de uma visita técnica em uma propriedade rural referência em produção agroecológica do assentamento Curral de Pedras, situada no município de Conceição do Araguaia (PA). Araújo et al. (2016) relatam que o encontro entre indígenas e agricultores foi muito produtivo e permitiu questionar alguns preconceitos relacionados ao paradigma agroecológico, como a suposta improdutividade e atraso tecnológico, além de ampliar a percepção dos estudantes sobre outras situações sociais e agroambientais.

Uma terceira modalidade de interação cultural associada à Agroecologia foi realizada pelo Conselho Indigenista Missionário (CIMI), através de intercâmbios exclusivamente com indígenas das etnias Myky, Tapirapé, Kayabi, Negarotê, Rikbatsa e Enawenê-Nawê. O CIMI atuou de 2011 a 2015 na preservação das sementes crioulas e da tradição alimentar e agrícola do povo Myky, na aldeia Japuíra, Território Indígena Menku, situado no município de Brasnorte (MT), conforme relatado por Ferraz, Filardo e Amarante (2016). Foram realizados intercâmbios de 
saberes e de sementes, mudas, estacas e afins, bem como a sensibilização para a preservação das tradições como forma de manutenção da autonomia, da soberania alimentar e do fortalecimento comunitário frente à erosão da agrobiodiversidade e cultural decorrentes do avanço do agronegócio e da urbanização.

Outra forma de intercâmbio foi estabelecida pelos Xukurú do Ororubá, que, envolvendo os residentes das várias aldeias da TI, realizou o II Encontro Urubá Terra, na aldeia Cana Brava, município de Pesqueira (PE); promovido por coletivos indígenas, o evento foi concebido a partir do próprio modo de ser Xukurú. Rodas de Toré abriram o evento, cuja programação contou com exposição dos trabalhos de resgate agrícola e de alimentos tradicionais produzidos pelas escolas, apresentações de teatro e organização de uma feira de trocas de saberes e sementes crioulas. Fechine e Tertuliano (2015) concluíram que o movimento de resgate cultural Xukurú é muito significativo para o fortalecimento do povo, sobrevivente de um longo histórico de repressão e etnocídio.

O povo Xukuru do Ororubá tem se destacado por sua história de resistência e força política. Araújo e Ordonio (2011) buscaram sumarizar sua trajetória e inserção social atual, que ocorre, por exemplo, através da produção de alimentos saudáveis. A feira livre de Pesqueira (PE) conta com 20 famílias do povo Xukuru do Ororubá, que comercializam localmente alimentos produzidos em sistemas agroecológicos. Os autores relatam a história agrária desta etnia até sua inserção contemporânea na cidade, paralelamente ao processo de demarcação territorial na Serra do Ororubá. Afirmam que, devido à participação nas feiras livres, as condições materiais das famílias melhoraram, além de ter possibilitado o reencontro de familiares distantes. A retomada de territórios tradicionais permitiu, portanto, a elevação da oferta de alimentos de qualidade na região, o que contribuiu para refutar preconceitos veiculados na região contrários à demarcação das terras indígenas.

Aprofundando esta perspectiva, Araújo et al. (2015;2015a;2015b) analisaram os encontros de agricultura e a inserção das políticas públicas nas aldeias e a relação do povo Xukuru com os municípios próximos. Para tanto, entrevistaram Xukurus do Ororubá (TI Serra do Ororubá), no município de Pesqueira (PE), a fim de caracterizar suas práticas agrícolas de base ecológica tradicional, complementando as observações em campo com pesquisas bibliográficas. Traçaram a trajetória histórica e geográfica de resistência e o empenho social pela manutenção da tradição agrícola. A inserção de forma qualificada nas feiras livres de dois municípios de Pernambuco e no Programa de Aquisição de Alimentos (PAA) permitiu uma melhoria na qualidade de vida e uma revalorização da tradição agrícola e alimentar. Os autores apontam para a conexão entre os ciclos e sinais da natureza, a espiritualidade Xukuru e os sistemas tradicionais de cura, considerados aspectos fundamentais desta tradição.

Entre os Guarani-Kaiowá, Brand, Colman e Costa (2008) procuraram compreender e correlacionar a cosmologia Guarani-Kaiowá e as ações de 
desenvolvimento rural realizadas na TI Caarapó, em Paranhos (MS), entre 1995 e 2004. Para tanto, entrevistaram diversos moradores visando caracterizar as perspectivas dos indígenas sobre sua história e as relações com diversas instituições que atuaram naquele contexto. A reflexão sobre as atividades de assistência técnica e extensão promovidas por atores diversos se mostra de alta importância, dada a complexidade dos impactos na organização sociocultural dos povos após tais atuações. Ressalta-se a necessidade de atuar junto aos integrantes das macrofamílias indígenas, respeitando as cosmologias específicas de cada uma e o modo como preferem adotar e utilizar as tecnologias trazidas do meio externo.

Outro aspecto a ser destacado é que as formas de organização das comunidades indígenas também se diferenciam em função dos diferentes contextos locais e históricos que se encontram. As transformações na organização social de aproximadamente trinta comunidades indígenas migradas para contextos periurbanos são analisadas por Cardoso, Ramalho e Py-Daniel (2007). O contexto envolve seis etnias indígenas, que iniciaram migrações para zonas periurbanas de Manaus (AM) desde os anos 50. Os autores apontam para as situações de precariedade material, falta de acesso à terra, endividamento das famílias e redução no patrimônio biológico e cultural, mas também a criação de novas redes sociais, produção multilocal, elevada biodiversidade nos territórios ocupados e integração entre espaços rurais e periurbanos - que são importantes adaptações e criações novas do ponto de vista agroecológico e socioambiental, que podem inclusive servir de inspiração para realidades de outros grupos identitários.

As atividades identificadas com a Agroecologia realizadas junto a diferentes comunidades indígenas, como veremos a seguir, também estão associadas à rediscussão das relações de gênero, à revalorização das práticas tradicionais, como os mutirões, a utilização de dinâmicas participativas, como o desenho permacultural, juntamente com a sua filosofia, o os Diagnósticos Rurais Participativos (DRPs) e também à avaliação dos impactos da inserção das comunidades em políticas públicas, como, por exemplo, o Programa Carteira Indígena e o Programa de Aquisição de Alimentos (PAA).

Oficinas e atividades realizadas com base em métodos participativos podem se constituir em espaços de criação, sensibilização e de reelaboração de percepções. Gama et al. (2007) realizaram uma oficina na TI Serra do Padeiro, em Buerarema (BA), que estimulou uma percepção crítica sobre a atual divisão sexual do trabalho, um tema recorrente no movimento agroecológico. Esta experiência evidenciou as diferenças das perspectivas feminina e masculina entre os Tupinambá, com base na confecção e comparação de bonecos de argila por homens e mulheres, visando a representação das ocupações dos gêneros no cotidiano. Criatividade, multidimensionalidade, segurança alimentar e educação foram associadas às mulheres, e os atributos de esforço físico, como preparo da lenha, fabrico de farinha, preparo de terreno agrícola, plantio em escala e comercialização foram associadas aos homens. É 
interessante notar que os atributos femininos são relacionados pelos autores a uma maior aceitação de algumas técnicas agrícolas agroecológicas gestadas em outros espaços.

Atividades associadas à Agroecologia nas Tls podem também recorrer à permacultura, como as realizadas e analisadas por Vasconcelos (2009) e Vasconcelos, Alardo Souto e Alves (2011) junto às comunidades indígenas Kaimbé, da terra indígena Icó-Várzea (bacia do Rio Itapirucu, Bahia). Os autores relatam que as oficinas objetivaram auxiliar os indígenas a sublevar a degradação ambiental e social com base na permacultura. O planejamento participativo de uma residência foi realizado e executado através de mobilização em mutirões, que implementou sistemas agrícolas ecológicos e bioconstruções, oriundas de matéria-prima de baixo impacto ambiental, presentes no território; além disso, avaliam que reflexões críticas sobre problemas cotidianos e planejamento de mudanças são alguns dos resultados positivos obtidos.

Em um projeto de pesquisa-ação na comunidade Kokama Kunumi Kawki, em Manaus, (AM), foi implementada uma horta comunitária, por meio da articulação de um mutirão. A melhoria na qualidade nutricional e a geração de renda, bem como o fortalecimento das relações comunitárias e preservação dos recursos naturais estão entre resultados do trabalho realizado por equipe do Instituto Federal do Pará (IFPA), da Universidade Federal do Oeste do Pará (UFOPA) e da Empresa Brasileira de Pesquisa Agropecuária Amazônia Oriental (EMBRAPA Amazônia Oriental) junto à comunidade Kokama. Um representante indígena indicou que o emprego de tecnologias simples e o resgate do saber tradicional são fundamentais em projetos que integrem pesquisadores, estudantes e comunidades tradicionais. A pesquisa-ação gerou dados valiosos para emprego em outras comunidades, segundo Correa Neta et al. (2016).

Oliveira (2016) relata a oficina de cultivo de mandioca que realizou através do Instituto Federal do Amazonas (IFAM), com apoio da Organização das Nações Unidas (ONU), junto às comunidades indígenas de Tabatinga (AM). Foram promovidas discussões sobre a produção agroecológica e as modificações voltadas para o aprimoramento técnico e tecnológico do cultivo da mandioca na comunidade. Entre os obstáculos para um aprimoramento das condições de vida da comunidade estavam a falta de água potável, a venda para atravessadores e a destinação de resíduos.

As propostas agroecológicas podem gerar um grande interesse nas comunidades indígenas. A partir de demanda da comunidade indígena Guató, da ilha Ínsua (MS), a Embrapa Pantanal realizou um diagnóstico rural participativo e entrevistas com os moradores a fim de conhecer o histórico de uso da terra e a aptidão para a produção agroecológica. Piovezan, Campolin e Feiden (2007) relatam que quase todos integrantes da aldeia participaram da reunião, o que demonstra o grande interesse e a predisposição para a criação de sistemas produtivos alternativos, que já vinham sendo praticados dispersamente na comunidade. 
Por outro lado, como parte dos projetos vinculados à Agroecologia são realizados a partir da captação de recursos públicos, e como os projetos, em vários casos, são conduzidos pelas próprias organizações indígenas, há a necessidade de se avaliar os processos administrativos, gerenciais e burocráticos neste processo - e seus impactos sobre as manifestações não formais de organização indígena. Neste sentido, a relação entre as organizações formais dos indígenas e o universo administrativo estatal foram analisadas por Costa (2012), que levantou percepções de residentes das TIs Itaóca e Piaçaguera, em Mongaguá e Peruíbe (SP), sobre dois projetos realizados no âmbito do Programa Carteira Indígena, em 2005. Os projetos realizados com famílias TupiGuarani e Guarani envolveram a implantação de roças comunitárias, aquisição de mudas e plantio, além de revitalização de uma Casa de Cultura. Ressalta a autora que o acesso ao edital por meio de uma associação indígena marca um protagonismo incomum, o que não impediu o surgimento de diversos problemas administrativos. Ressalta ainda que as políticas agroecológicas precisam ser construídas a partir de um diálogo efetivo com as tradições de cada povo, o que inclui um foco sobre o componente burocrático-administrativo.

De forma semelhante, Teixeira (2016) constatou que muitos entraves foram enfrentados na inserção de 27 famílias da TI Caramuru Catarina Paraguaçu, do povo Pataxó Hãhãhãe, no Programa de Aquisição de Alimentos (PAA), entre 2014 e 2015. Destaca que, apesar da inadequação dos procedimentos burocráticos diante da realidade indígena, foi possível alcançar diversos objetivos sociais e econômicos. Os entrevistados relataram melhoria na qualidade de vida e um aumento na segurança alimentar, através da diversificação da produção e da garantia de comercialização da produção. Foi identificada uma importante atuação das mulheres nesta política pública. Segundo a autora, as mulheres foram responsáveis por um aprimoramento na organização social, com grande destaque na tomada de decisões, e nos encaminhamentos voltados para uma eficiente inserção no Programa.

A análise das experiências selecionadas evidencia a pluralidade de sujeitos indigenistas, as diversas manifestações concretas das propostas agroecológicas, as múltiplas situações socioculturais indígenas e por vezes em dinâmicas particulares de migrações e mobilidades. Algumas experiências foram exitosas e bem recebidas pelas comunidades; outras, elaboradas sem participação indígena, realizadas conforme exigências burocráticas e modus operandi verticalizados, pouco dialógicos em relação às organizações indígenas. De qualquer forma, pode-se afirmar a dimensão organizacional e as novas formas de interação com atores e instituições sociais ampliam a diversidade sociocultural e política entre as comunidades indígenas, ao mesmo tempo que representa um rico mosaico de experiências visando a revalorização da cultura indígena e das práticas sustentáveis. 


\section{Educação em agroecologia nas terras indígenas}

Em relação à educação, há nas publicações encontradas o registro e análise de um diferenciado conjunto de atividades, em geral pontuais e eventuais, em diferentes formatos e durações, abordando temas relacionados à alimentação, saúde e práticas agroecológicas, além de cursos técnicos de nível médio ofertados para apenas uma turma, com metodologia de alternância, interações entre indígenas e agricultores familiares do entorno, ou ainda a adoção de práticas agroecológicas em escolas de ensino médio no interior de Tis. Nota-se a importância da Agroecologia como referencial técnico e teórico para atividades realizadas no campo educacional.

Com relação às atividades eventuais realizadas fora do ambiente escolar, Araújo, Sousa e Wara (2015) desenvolveram, junto aos SateréMaué, atividades em duas TIs no Amazonas, com o objetivo de abordar temas de educação ambiental e a importância da preservação da biodiversidade e da cultura local, além de promover diálogos sobre segurança alimentar e práticas agroecológicas que permitem otimizar o uso dos recursos naturais e melhoram o funcionamento e qualidade do sistema produtivo. Cardoso et al (2011) também abordaram o tema da segurança alimentar com os Maxakali da TI Aldeia Verde, em Ladainha, Vale do Mucuri (MG). Atualmente, se encontram em uma área com características que impossibilitam o cultivo de roças e a caça, o que favorece o consumo de produtos industrializados. Após a constatação de um estado nutricional inadequado em todas as faixas etárias, foram elaboradas rodas de conversa e oficinas que discutiam seus hábitos alimentares então vigentes, enaltecendo a autoestima, a identidade coletiva e os saberes tradicionais.

As iniciativas podem explorar todo a complexidade e riqueza de conhecimentos agroecológicos envolvidos na criação de hortas escolares. Baltazar et al (2014), através da construção de uma horta na Escola Estadual Indígena do Ensino Médio Pastor Reginaldo Miguel, na TI Lagoinha, composta pela etnia Terena, no Distrito de Taunay, Aquidauana (MS), trabalharam diversos assuntos relacionados à educação ambiental, como a etnomatemática e a importância de uma alimentação mais saudável e diversa, em especial em famílias com integrantes diabéticos ou com pressão arterial alterada. As verduras colhidas na horta foram direcionadas à merenda da escola indígena. Metade dos alunos implementou um sistema semelhante em seus domicílios e, além do consumo pela própria familiar, passaram a comercializar os excedentes em uma feira local.

No mesmo sentido, entre novembro e dezembro de 2014 aconteceram as práticas realizadas em Umariaçu II - Eware e Assentamento Novo Paraíso com o objetivo de integrar alunos e agricultores, indígenas e não indígenas, através de duas aulas multidisciplinares e práticas com enfoque em Agroecologia, aproximando o conteúdo teórico do experimental. Entre as atividades destacam-se o levantamento de espécies da propriedade, manejo de colônias melíponas, 
construção de canteiros em forma de mandala, plantio e elaboração de compostagem orgânica. Práticas favoreceram troca de saberes entre os produtores, que estavam no papel de alunos, além de troca de semente, diversificando as espécies. A prática realizada em um quintal agroflorestal numa área pequena e com abundância de espécies, reforçou a importância da biodiversidade e sua manutenção (OLIVEIRA et al., 2015).

A presença da Agroecologia pode estar associada a uma reorientação pedagógica visando uma educação crítica e focada na revalorização da cultura indígena, seus saberes e formas de organização. Nascimento et al. (2007) relatam a rica união de profissionais de diversas áreas, durante o II Estágio de Vivência e Difusão da Agroecologia em Área Indígena, visando romper com o método de ensino convencional e buscar uma educação com base no diálogo e que leva em consideração os saberes presentes nas comunidades e as possibilidades de construção de uma relação sociedade-natureza mais equilibrada e sustentável. Dentre as atividades descritas está a criação de mapas êmicos pelos estudantes, atividades holísticas com os educadores infantis e pais dos alunos, jogos didáticos para integração e discussão de conceitos ecológicos, manejo da horta e preparação de um filme sobre o dia-a-dia da aldeia.

Ainda no campo da educação não formal, mas na forma de cursos, Melo e Sant'ana (2014) analisaram a construção e execução de curso de formação continuada em agricultor florestal, oferecido em apenas uma edição, realizado na TI Cachoeirinha, formada pela etnia Terena, em Miranda (MS). A experiência foi considerada positiva e indicada como inspiradora para outros possíveis trabalhos em Tis. O processo foi enriquecido com a participação da comunidade e as aulas foram ministradas por professores indígenas ou com conhecimento sobre produção agrícola indígena; os conteúdos educativos valorizaram o saber tradicional, em contraponto à agricultura convencional.

Outro exemplo a ser citado é o do Programa Aldeia Produtiva, promovido pelo Governo do Estado de Mato Grosso do Sul, que vinha promovendo a capacitação de agricultores da etnia Guató/Kamba em Corumbá (MS). A iniciativa consistiu na oferta de dois dias de atividades teóricas e práticas para a construção de hortas que podiam ser direcionadas ao consumo próprio e/ou comercialização para a merenda escolar, com potencial para a geração de renda e melhoria na qualidade da alimentação. Houve expressiva participação de jovens e a elaboração de um documentário, além da disseminação do conhecimento agroecológico e extensão rural em comunidades indígenas mais isoladas (SILVA, 2010).

Vale destacar que existem cursos regulares em Agroecologia no campo da educação formal para comunidades indígenas. Campos e Binotti (2015) descrevem o curso técnico de Agroecologia realizado no âmbito do Pronatec (Programa Nacional de Acesso ao Ensino Técnico e Emprego) ofertado também para uma única turma em São Gabriel da Cachoeira (AM). Foram elaborados trabalhos que relatam a realidade dos estudantes e apresentados ensinamentos agroecológicos e sobre a 
criação de aves e hortas na comunidade. A área experimental destinada às práticas vinha sendo até então utilizada com agrotóxicos. Entre os problemas encontrados estavam o atraso no pagamento de bolsas e na disponibilização de alimentação e a falta/limitação de estágios. Os autores recomendam a utilização do conceito de transição agroecológica nas atividades ensino, de forma a revalorizar os saberes tradicionais e a atuação dos movimentos sociais, contribuindo assim para a soberania alimentar dos povos indígenas que ali habitam.

Outra experiência de realização de cursos e nível médio, envolvendo diversas etnias no sudeste do Pará, ocorreu através da criação do curso Técnico em Agroecologia integrado ao Ensino Médio, relatado por Araújo et al. (2011). O curso teve a duração de 3 anos e foi dividido em 3 ciclos, visando a conexão entre a formação técnica do jovem e a etnociência, com princípios de sustentabilidade aplicados aos territórios indígenas. Houve o ingresso de 39 alunos de oito povos, o que resultou na integração e na comunicação e articulação política entre as diferentes culturas. Também foram produzidos calendários e inventário de práticas culturais, além de mapas e planos de estudo, pesquisa e trabalho que deveriam ser aplicados no ciclo subsequente, com foco nos hábitos alimentares. Há o desafio de envolver todas as terras indígenas da região, além do resgate e revitalização da cultura de cada povo, de forma a fortalecer o processo de construção e a troca de conhecimento dos envolvidos.

Além disso, registra-se que algumas escolas de ensino médio nas Tis passaram a adotar princípios e práticas agroecológicas. É o caso das atividades relatadas por Lopez (2016) junto aos Kaingang na TI Apucaraninha (Tamarana, PR). Após análise de entrevistas com membros da comunidade, compara-se o sistema de ensino que vinha sendo realizado em uma escola no distrito mais próximo à $\mathrm{TI}$, com o ensino que passou a ser ofertado, posteriormente, no interior da aldeia, que passou a abordar, além do conteúdo programático comum, a agroecologia e alguns conceitos que valorizam a cultura indígena e sua importância para a identidade desse povo. Alunos, ex-alunos, professores e lideranças mencionaram a importância da criação da escola e ressaltam seu papel na qualidade de vida, assim como a valorização de sua cultura e costumes. Houve a criação de um grupo de dança e espaços de mobilização e articulação da juventude, além do resgate da festa tradicional do Parí. Identificou-se a necessidade de adequação do plano de ensino visando ampliar sua interculturalidade e interdisciplinaridade, com base no diálogo.

Uma iniciativa similar ocorreu na Terra Indígena Te'yikue, em Caarapó (MS), Marques et al (2012) mostram que houve um empoderamento da comunidade Guarani Kaiowa através da criação de um sistema de ensino com propostas de formação crítica e valorização dos conhecimentos tradicionais. Como parte do conteúdo programático, os alunos fizeram muitas práticas, incluindo a criação de uma horta agroecológica em suas casas, implantação de pequenos módulos agroflorestais e mutirões com apoio dos pais e professores, aproximando 
a família da escola. O plano de ensino que teve a participação da comunidade aborda temas como religião, língua nativa e a importância da terra.

Barbosa et al. (2014) descrevem a aplicação da metodologia de alternância utilizada no curso Superior de Tecnologia em Agroecologia, no município de Glória de Dourados (MS) com jovens Terena. Os estudantes que seguiram essa metodologia puderam aplicar os conhecimentos teóricos na comunidade, observar os sistemas de produção presentes na comunidade, acessar os saberes indígenas e tomar consciência de sua realidade e dos problemas enfrentados.

\section{Extensão rural agroecológica e gestão ambiental}

A Extensão Rural Agroecológica e a Gestão Ambiental vêm se apresentando como referência teórica para o estabelecimento de relações com os povos tradicionais, em especial os indígenas. No Brasil, pesquisas relevantes relacionadas ao tema evidenciam que a interação de técnicos agrícolas e pesquisadores de unidades educacionais deve considerar aspectos culturais que são reveladores da importância da preservação da natureza para esses povos como componente indispensável à sua reprodução social. Neste sentido, destacam-se as práticas de reflorestamento e de conservação da biodiversidade, a relação dos povos com a natureza e as reflexões sobre o trabalho dos extensionistas em campo.

Em relação as práticas de reflorestamento e conservação da biodiversidade, importante trabalho foi realizado por Carraro, Pocal e Peixer (2015). Entre 2012 e 2014, indígenas Xokleng, em parceria com o Centro Vianei de Educação Popular, situado em Lages (SC), e outras entidades educacionais, se organizaram com o intuito de promover práticas ambientais na Aldeia Bugio e a Aldeia Takuaty. Durante os dois anos da experiência foi possível recuperar 50 hectares de áreas via sistema agroflorestal com base no manejo agroecológio, capacitar os indígenas para a produção de mudas e fazer a integração entre a comunidade e o mercado de carbono. A construção de um viveiro de mudas buscou o fortalecimento de atividades produtivas sustentáveis, o que se desdobrou na troca de saberes e fortalecimento da cultura indígena. A ação, que na prática buscava a recuperação de áreas degradadas na região, propiciou o diálogo intercultural sobre a importância da concepção de natureza e da cosmologia do grupo, incencivando assim a retomada de práticas tradicionais.

No Estado do Mato Grosso do Sul, a pesquisa-ação realizada entre a Universidade Católica Dom Bosco (UCDB) e as comunidades indígenas Guarani Kayowá da região desenvolvida como atividade de extensão para busca de soluções de problemas locais resultou também em conhecimento científico produzido pelos acadêmicos, como especifica Brand e Marinho (2011). Foram construídos viveiros e represas para a 
recuperação e gestão ambiental do território; também foram realizadas oficinas sobre cultivo de alimentos, criação de animais para alimentação familiar, beneficiamento de alimentos e artesanato, o que propriciou a formação de professores e técnicos indígenas. Dessa forma, ficou evidenciado que a pesquisa participativa proporciona a construção do conhecimento que responde aos problemas da realidade social local e que os projetos de extensão criam uma possibilidade de troca e diálogo entre universidade e comunidade.

Para a propagação de práticas como estas é necessário colocar em evidência os problemas sócio-ambientais específicos em cada comunidade e indicar alternativas viáveis para a implantação de formas de produção agroecológica, como relatado por Rodrigues e Nishikawa (2007), na Terra Indígena Vanuíre, munícipio de Arco Íris (SP). Os autores constataram diversas situações de degradação ambiental e nas condições do solo, caracterizado como arenoso e deficiente para a produção de alimentos, além de alto índice de erosão. O resultado da análise difere da pesquisa realizada por Silva et al (2016) que encontrou elevados teores de carbono nas terras pretas indígenas, no município de Apuí (AM), o que demonstra a variedade de realidades pedológicas dos povos indígenas no Brasil. No caso da aldeia Vanuíre, onde moram indígenas Kaigangs e Krenaks, entre outros, os integrantes encontraram dificuldades para manter as atividades de subsistência e de geração de renda. Os autores recomendaram o incentivo e a valorização do trabalho das mulheres indígenas com as sementes para o artesanato e com o replantio de espécies arbóreas ao redor das casas. A atividade tem sido importante também para recomposição florestal da aldeia bem como para a segurança alimentar e a qualidade de vida das famílias.

Trabalho semelhante de diagnóstico foi realizado pelo grupo de Difusão da Agroecologia em Área Indígena formado, em 2006, na Universidade Federal Rural do Rio de Janeiro, como mostra Siqueira (2007). Com o objetivo de diagnosticar e caracterizar as nascentes do rio que abastece a população Pataxó, em Barra Velha (BA), foram realizadas conversas com moradores e buscado um entendimento em comum sobre o que é necessário fazer para preservar as nascentes. As práticas de base agroecológica também foram analisadas Lima, Xavier e Sapara (2015). Apesar da resistência em parte da comunidade, foi realizada uma experiência de implantação de hortas circulares em bases agroecológicas, contemplando uma integração entre produção vegetal e animal, no município de Amajari (RR).

A interação entre estudantes e profissionais de diversas áreas e a capacitação dos participantes para uma atuação no campo da Agroecologia são retratadas no trabalho de Weiss (2016), que mostra sua vinculação com a valorização de saberes ancestrais dos povos indígenas em um ambiente educacional a partir de atividade de extensão realizada pela Universidade Estadual do Rio Grande do Sul (UERGS) na Escola Estadual Indígena de Ensino Fundamental Mükej, na Terra Indígena do Guarita, município de Tenente Portela (RS). As atividades que envolvem a universidade e as comunidades são capazes de sensibilizar os envolvidos 
sobre questões ambientais, resgatar conhecimentos tradicionais e promover um aprimoramento na merenda escolar. Há ainda alguns importantes estudos sobre a interação dos indígenas com a natureza. Kriegel, Azevedo e Siva (2014) analisaram as relações entre os Guarani e o meio ambiente, particularmente das Terras Indígenas Araçai e Pindoty, minicípio de Piraquara, região metropolitana de Curitiba (PR). Os Guarani, com grande conhecimento ecológico e sobre a agrobiodiversidade, propiciaram reflexões sobre a produção agrícola convencional. Um aspecto importante da interação foi o reconhecimento de que é preciso adequar as ações com as demandas comunitárias de modo participativo, pois no modo de vida indígena estão intrísecos os significados místicos e uma relação íntima com a natureza. Ikuta e Barros (2006) e Ikuta (2007) também fizeram essa análise com os Mbya Guarani, da Terra Indígena da Varzinha, situada nos municípios de Caraã e Maquiné (RS), onde encontraram cerca de 40 espécies utilizadas tanto para alimentação confecção de artesanato e para fins medicinais. Percebeu-se que a reprodução social dos Guarani permanece associada à natureza e ao espaço territorial.

A diversidade e o uso de plantas pela comunidade Kaingang foram o objeto de estudo de Porsch (2013), que buscou a caracterização ecológica, identificação taxonômica e interpretações sobre a importância dessas plantas no dia a dia da comunidade da Terra Indígena da Guarita, no Rio Grande do Sul. Por meio da pesquisa, foram identificadas 78 espécies de plantas categorizadas em cinco diferentes modalidades: medicinal, alimentar, artesanato, ritualístico e outros. Algumas dessas plantas vinham sendo empregadas em mais de uma finalidade. $O$ autor afirma que a continuidade do uso de plantas pela comunidade é muito importante para a preservação da cultura Kaingang, que repassa 0 conhecimento para as novas gerações sob processos ritualísticos. Mas na ocasião do estudo, a comunidade não vinha conseguindo manter suas tradições alimentares como decorrência da situação de pobreza e de risco social em que se encontravam.

Afim de recuperar e reconhecer as bases culturais e conhecimentos tradicionais do modo artesanal de produzir a erva-mate, Fedrizzi e Ferreira (2015) relatam a experiência do Grupo de Viveiros Comunitários (GVC) e o grupo UVAIA de Agroecologia, ambos vinculados à Universidade Federal do Rio Grande do Sul (UFRGS), nos municípios de Panambi (RS), São Miguel das Missões (RS) e Guaraciaba (SC). As experiências foram baseadas na produção de erva-mate, troca de saberes, interação entres os participantes das vivências e transmissão de conhecimento intergeracional. Como resultado foi observado que as vivências contribuiram para a transformação de relações sociais com os alimentos e com a produção, mostrando que é possível realizar a produção própria do que se consome e assim ampliar a autonomia e a autossuficência para as comunidades.

No mesmo sentido, Costa (2009) ressalta que, apesar da importância dessas práticas realizadas nas terras indígenas que ajudam a preservar a diversidade social no Brasil, há diversos desafios quando se 
procura trabalhar com foco na demanda específica de cada povo. Smith e Guimarães (2010) fizeram uma relevante reflexão a partir de uma base documental sobre a relevância de se utilizar os aprendizados já obtidos, que, no caso, apontam diversas experiências na Amazônia visando a construção de políticas que apoiem os povos indígenas a condtruir a sustentabilidade ambiental dos seus territórios.

Soares (2013) apresenta um conjunto de questões e reflexões sobre a extensão rural indígena com o povo Guarani, no Rio Grande do Sul. Entre 2004 a 2012, foram implantadas unidades didáticas (UD) que permitiram um processo de extensão participativo. No total, 24 aldeias, 359 famílias e 1.847 pessoas foram beneficiadas com um projeto de segurança alimentar; os extensionistas foram identificados como facilitadores do processo preservação da cultura indígena. O autor ressalta que é necessário considerar a percepção indígena para a construção de políticas públicas. A Assistência Técnica e Extensão Rural Indígena (ATER) realizada de forma participativa agrega ao plano de trabalho características culturais que são diferentes daquelas encontradas entre agricultores familiares - e que auxiliam os técnicos nas aldeias.

O processo participativo também contribui para a interpretação que os extensionistas elaboram de seu trabalho. Gonçalves e Lima (2016) analisaram as percepções dos extensionistas do Instituto Agronômico de Pernambuco (IAP) sobre o trabalho que vinham desenvolvendo com as comunidades indígenas nas regiões do Agreste e do Sertão do Pernambuco e destacam o desconhecimento histórico por parte dos extensionistas sobre a temática indígena, a reduzida reflexão sobre a "especificidade étnica", a pouca aderência à gestão ambiental territorial e à Agroecologia, além da falta de planejamento de trabalho. Nesse sentido, apesar dos profissionais de Ater reconhecerem os povos indígenas como público prioritário, verifica-se pouca qualificação em relação à especificidade indígena e a vigência de posturas comportamentais preocupantes.

O diálogo entre diferentes ramos da ciência, como, por exemplo, as áreas de Agroecologia e Antropologia, é analisado por Lopes e Bezerra (2011). No trabalho realizado nas Terras Indígenas Tremembé de Queimadas e Telhas, em Acaraú (CE), identificaram aspectos negativos e positivos para o desenvolvimento sustentável das aldeias em uma análise sobre atividades de formação em práticas agroecológicas. Nesta experiência, dez famílias implantaram sistemas agroecológicos e vinham obtendo renda e acessando programas sociais, enquanto outras consideraram a mudança na forma de manejo muito brusca em relação à que vinha sendo praticada. Nesse sentido, a construção participativa do plano de trabalho permite contemplar as diferentes opiniões para não considerar somente as bases agroecológica, mas também as antropológicas, considerando assim aspectos como a história e a cultura de cada povo. 


\section{Considerações finais}

Neste estudo de revisão, foi identificado um total de 92 publicações em em periódicos científicos, livros, teses e dissertações, dentre as quais 42 foram publicados na forma de artigo na revista Cadernos de Agroecologia São publicações, em grande parte apresentadas previamente em edições do Congresso Brasileiro de Agroecologia; além destes, outros 23 artigos na Revista Brasileira de Agroecologia. Isso mostra que $70 \%$ das publicações científicas em periódicos encontradas nesta pesquisa está relacionada à rede de pesquisadores e extensionistas organizada pela Associação Brasileira de Agroecologia (ABA), fortemente vinculada aos movimentos sociais e a atividades de extensão. Em outros períodicos as publicações sobre o tema são muito menos frequentes. Foram também encontradas 10 dissertações de mestrado e uma tese de doutorado, além de algumas poucas publicações em livros.

As atividades identificadas com a noção de Agroecologia foram realizadas com comunidades de diferentes regiões, biomas e etnias. $\mathrm{O}$ levantamento bibliográfico aqui apresentado traz informações sobre as características de experiências junto a aproximadamente 50 etnias, com a participação de dezenas de instituições de ensino e pesquisa, organizações não-governamentais e outras. Neste sentido, as ações promovidas com base na Agroecologia representa, entre outros aspectos, a construção de novas formas de interação com atores e instituições sociais externas às comunidades.

Os diversos relatos apresentados evidenciam que as ações agroecológicas buscam uma revalorização da cultura, das tradições e da identidade social, em geral de forma articulada com inovações técnicas que, partindo dos valores e interesses das próprias comunidades, fomentam a constituição de sistemas agroecológicos eficientes e adaptados, o manejo florestal sustentável e a formação de sistemas agroflorestais, com a prioridade para métodos participativos e dialógicos visando o empoderamento das comunidades, a reflexão sobre as relações de gênero, o aprimoramento dos hábitos alimentares e da gestão ambiental e, entre outros aspectos, a reorientação das atividades de ensino e de extensão. 


\section{Referências bibliográficas}

ALMEIDA, T. V. V., A agrobiodiversidade nas terras indígenas Guarani Nhandewa no norte do Paraná: memória, resgate e perspectivas. Araras: Universidade Federal de São Carlos, Dissertação (Mestrado em Agroecologia e Desenvolvimento Rural), 2012.

ALVES, J. C.; DIAS, B. P. Quintal Agroflorestal em Terra Indígena Guarani-Kaiová Aldeia Panambizinho, Dourados, MS. Cadernos de Agroecologia, v. 9, n. 4, p. 1-4, nov. 2014.

ARAÚJO, A.L.O.; ORDONIO, I. N. Feira Xukuru do Ororubá: Conquistas em torno de uma Experiência de Comercialização de Alimentos de Base Ecológica. Cadernos de Agroecologia, v. 6, n. 2, p. 1-5, dez. 2011.

ARAÚJO, A.L.O. Consumidores da Feira Xukuru do Ororubá de Alimentos de Base Ecológica em Pesqueira, PE, 2013: Panorama Geral e Derivações Iniciais. Cadernos de Agroecologia, v. 9, n. 4, fev. 2015a.

ARAÚJO, A. L. O. et al. Os dois primeiros Encontros de Agricultura do Povo Xukuru do Ororubá, Pesqueira- PE: Materialização do encantamento e contraponto à Política de Distribuição de Sementes. Cadernos de Agroecologia, v. 10, n. 3, p. 1-6, 2015 b.

ARAÚJO, M. I. de; SOUSA, S. G. A. de; WARA, S. G. A (re) educação ambiental com práticas agroecológicas na comunidade Sateré-Mawé. In: Fórum Internacional de Pedagogia, 7. 2015, Parintins. A Pesquisa na graduação: dialogicidade, autonomia e formação de professores. Campina Grande: Realize Editora, 2015. v. 1, n. 4.

ARAÚJO, M. G. et al. Agricultura de base ecológica Xukuru e comercialização: a concretização de um sonho coletivo. Cadernos de Agroecologia, v. 10, n. 3, p. 1-6, 2015.

ARAÚJO, W. B. S. et al. Ênfase agroecológica na formação de indígenas: a experiência do Curso Técnico em Agroecologia dos povos indígenas do sudeste paraense. Cadernos de Agroecologia, v. 6, n. 2, p. 1-5, dez. 2011.

ARAÚJO, W.B.S. et al. Bem viver no campo: uma prática possível: intercâmbio entre jovens indígenas e agricultores com produção agroecológica. Cadernos de Agroecologia, v. 10, n. 3, maio 2016.

BALDUS, H., Bibliografia Crítica da Etnologia Brasileira, vol I, São Paulo: Kraus Reprint, Nendeln, Liechtenstein, 1954

BALDUS, H., Bibliografia Crítica da Etnologia Brasileira, vol. II, Hannover: Kommissionsverlag Münstermann-Druck, 1968.

BALliViÁN, J. M. P.; VENTURA, C.; OliveIRA, F. B. In Ti Fy Si - Casa das sementes antigas: uma experiência indígena kaingang. Agriculturas, v. 4, n. 3, p. 6-9, out. 2007. 
BALTAZAR, P.; CABO, L. V.; MARQUES, L. Horta na escola indígena da Aldeia Lagoinha, Aquidauana, MS. Cadernos de Agroecologia, v. 9, n. 4, p. 1-4, nov. 2014.

BARBOSA, V. S. et al. Pedagogia da Alternância como Promotora da Fixação de Jovens Indígenas na Comunidade. Cadernos de Agroecologia, v. 9, n. 4, p. 1-4, nov. 2014.

BARRETO, L.; CASTRO, M. S. Conservação do umbuzeiro (Spondias tuberosa) e de seus polinizadores no contexto agroecológico para a agricultura familiar indígena Pankararé no semi-árido. Revista Brasileira de Agroecologia, v. 2, n. 2, p. 1580-1583, out. 2007.

BIANCHINI, F.; BIANCHINI, P. C. Os agentes agroflorestais indígenas do Acre. Agriculturas, v. 4, n. 2, p. 18-20, jul. 2007.

BIANCHINI, P. C. Agroflorestas e agentes agroflorestais indígenas no Acre. Florianópolis: Universidade Federal de Santa Catarina, Dissertação (Mestrado em Agroecossistemas, 2006.

BRAND, A. J.; COLMAN, R. S.; COSTA, R. B. Populações indígenas e lógicas tradicionais de desenvolvimento local. Interações, Campo Grande, v. 9, n. 2, p. 171-179, jul./dez. 2008.

BRAND, A. J.; MARINHO, M. Extensão, pesquisa-ação e desenvolvimento local: articulação entre universidades comunitárias e povos indígenas. Em Extensão, Uberlândia, v. 10, n. 1, p. 9-25, jan./jun. 2011.

BRANDENBURG, A. Movimento agroecologico: trajetória, contradições e perspectivas. Desenvolvimento e meio ambiente: caminhos da agricultura ecológica. Curitiba: Editora da UFPR, 2002.

BUCHILLET, D. Bibliografia crítica da saúde indígena no Brasil (1844-2006). Quito: Abya-Yala; 2007.

BUENO, Y.M.; ARMANDO, M.S.; SUGASTI, J.B., Sensibilização agroflorestal na reserva indígena Krahô: o relato de uma experiência. Revista Brasileira de Agroecologia, vol. 2, n. 2, p. 525-528, out. 2007.

CAMPOS, M. L. de; BINOTTI, T. C. O ensino da Agroecologia em São Gabriel da Cochoeira-AM - contribuições reflexivas sobre o PRONATEC. Cadernos de Agroecologia, v. 10, n. 3, p. 1-6, 2015.

CANISO, M. P. Coletando hoje, pensando no amanhã: manejo comunitário participativo do Tucumã (Astrocaryum aculeatum) na Terra Indígena Apurinã do 45, Boca do Acre, Amazonas, Brasil. Revista Brasileira de Agroecologia, v. 1, n. 1, p. 473-476, nov. 2006.

CAPORAL, F. R.; COSTABEBER, J. A. Agroecologia e desenvolvimento rural sustentável: perspectivas para uma nova Extensão Rural. Agroecologia e Desenvolvimento Rural Sustentável, Porto Alegre, v.1, n.1, p.16-37, jan./mar. 2000. 
Espaço Ameríndio

CARDOSO, N. V. et al. Educação popular na Aldeia Verde Maxakali: Diálogo sobre a alimentação. Cadernos de Agroecologia, v. 6, n. 2, p. 1-5, 2011.

CARDOSO, T. M.; RAMALHO, A. L. M.; PY-DANIEL, V. A construção do espaço agroecológico por comunidades indígenas peri-urbanas (Manaus - Amazonas). Revista Brasileira de Agroecologia, v. 2, n. 2, p. 517-520, out. 2007.

CARDOSO, T. Manejo da agrobiodiversidade na agricultura indígena de corte e queima do baixo rio Negro, Amazonas, Brasil. Revista Brasileira de Agroecologia, v. 4, n. 2, p. 2180-2183, nov. 2009.

CARRARO, J. L.; POCAI, L. H.; PEIXER, Z. I. O Povo que Caminha sob o Sol: A Experiência do Projeto Carbono Social em Rede no Território Indígena Laklã Nõ. Cadernos de Agroecologia, v. 9, n. 4, p. 1-8, nov. 2015.

CARVAlHO, S.; CARVAlHO, F. e GALAN, M.C., Bibliografia Crítica dos Povos Aruák do Mato Grosso do Sul e do Grande Chaco. São Paulo: Terceira Margem, 2001.

CASTRO, A.P. et al., O etnoconhecimento agroecológico dos caboclos-ribeirnhos no manejo sustentável de sistemas agroflorestais na Amazõnia Ocidental. Revista Brasileira de Agroecologia, vol. 2. n. 2, p. 1288-1231, out. 2007.

CORREA NETA, G. et al. Horta comunitária como lócus propagador do conhecimento agroecológico. Cadernos de Agroecologia, v. 10, n. 3, maio 2016.

COSTA, R. M. G. F. Políticas públicas em agroecologia para os povos indígenas: um estudo de caso sobre o Programa Carteira Indígena na Baixada Santista. Araras: Universidade Federal de São Carlos, Dissertação (Mestrado em Agroecologia e Desenvolvimento Rural, 2012.

COSTA, R. M. G. F. Projetos Agroambientais em Terras Indígenas: Perspectivas atuais sob a ótica do etnodesenvolvimento. Revista Brasileira de Agroecologia, v. 4, n. 2, p. 1772-1775, nov. 2009.

DELWING, A. B.; GUADAGNIN, D. L.; CALCANHOTO, F. A.; KOCLL, V. Relações etnoambientais de uma comunidade indígena Mbyá Guarani: evidências de manutenção de conhecimentos e técnicas tradicionais. Revista Brasileira de Agroecologia, vol. 1 n.1, nov. 2006.

DIAS, T. A. B. et al. Agrobiodiversidade indígena: feiras, guardiões e outros movimentos. In: SANTILLI, J.; BUSTAMANTE, P. G.; BARBIERI, R. L. (Ed.). Agrobiodiversidade. Coleção Transição Agroecológica, n. 2, Cap. 8, p. 193-221. Brasília: Embrapa, 2015a.

DIAS, T. A. B.; PIOVEZAN, U.; SANTOS, N. R.; ARATANHA, V.; SILVA, E. O., Sementes tradicionais Krahô: história, estrela, dinâmicas e conservação. Revista Agriculturas: experiências em agroecologia, v. 11, n. 1, p. 9-14, abril 2014.

DIAS, T.; MORAES, C.; CASTRO, L.; MACIEL, M. Feiras de sementes em terras indígenas brasileiras. In: Congreso Latinoamericano de Agroecologia, 5, 2015, La Plata. 
Espaço Ameríndio

Memorias... La Plata: Sociedad Científica Latinoamericana de Agroecología, 2015. B5383.

DIAS, T.A.B. et al. Diálogos agroecológicos com agricultores indígenas: conservação da agrobiodiversidade e segurança alimentar. Cadernos de Agroecologia, v. 9, n. 3, p. 1-5, 2014a.

DUARTE, Z. G.; MARTINS, J.; AGUILAR, R. A. S. Práticas Agroflorestais em Terras Indígenas Guarani Kaiowá no Mato Grosso do Sul. Cadernos de Agroecologia, v. 9, n. 4, p. 1-5, nov. 2014.

FECHINE, R.; TERTULIANO, A. Relato do II encontro Urubá Terra (Povo Xukuru do Ororubá, Aldeia Cana Brava). Cadernos de Agroecologia, v. 10, n. 3, p. 1-6, 2015.

FEIJÓ, C. et al. O conhecimento tradicional em sementes crioulas: uma experiência vivenciada na Terra Indígena Guarita. Cadernos de Agroecologia, v. 8, n. 2, p.1-5, nov. 2013.

FEIJÓ, C.; ANTUNES, F. I. A.; PEREIRA, G. L. O manejo da agrobiodiversidade sob a perspectiva Mbya Guarani: um estudo de caso no litoral gaúcho. Cadernos de Agroecologia, v. 9, n. 4, p. 1-10, nov. 2014.

FERNANDES, R.S.; SILVA, D.; MACEDO, R.L., Experiência de implantação da meliponicultura como componente agroflorestal em comunidades indígenas do Rio Içana (AM), Revista Brasileira de Agroecologia, vol. 4, n. 2, p. 649-652, nov. 2009.

FERRAZ, Rodolfo Oliveira; FILARDO, Natalia Bianchi. Soberania alimentar do povo indígena da etnia Myky: exemplo de resistência. Cadernos de Agroecologia, v. 10, n. 3, maio 2016.

FERREIRA, S.G.; FERRAZ, E. L.; BARBOSA, S.G.A resistência cultural na tessitura de luta pela terra. Cadernos de Agroecologia, v. 10, n. 3, p. 1-4, 2015.

FERREIRA, T.B.; SABLAYROLLES, M.G.P. Roçados Borari: Identidade, Magia e conservação da natureza. Cadernos de Agroecologia, v. 9, n. 4, nov. 2014.

GAMA, E. V. S. et al. Divisão de trabalho entre homens e mulheres na Aldeia Indígena Tupinambá de Serra do Padeiro, Buerarema - BA. Revista Brasileira de Agroecologia, v. 2, n. 2, p. 1669-1673, out. 2007.

GONÇALVES, M. N.; LIMA, I. S. Concepções dos profissionais de Ater sobre as atividades extensionistas desenvolvidas em áreas indígenas em Pernambuco. Revista Brasileira de Agroecologia, v. 11, n. 2, p. 117-128, jul. 2016.

GUIMARÃES, B. V. C.; COSTA, I. J. Silva; CUNHA, L. M. V., SANTOS, V. M.; GOMES, R. R. Interação de culturas e sustentabilidade em comunidades indígenas. Cadernos de Agroecologia, vol. 6, n. 2, dez. 2011.

HARTMANN, T. Bibliografia Crítica da Etnologia Brasileira, vol. III, Berlin, Volkerkundliche Abhandlungen, 1984. 
HECKLER, J. M. Sementes e saberes... Trocas e aprendizados com a cultura Guarani e a agroecologia. Porto Alegre: Universidade Federal do Rio Grande do Sul, Dissertação (Mestrado em Educação, 2006.

IKUTA, A. R. Y. Transcender o campo agronômico na busca de sustentabilidade de comunidades indígenas Mbyá Guaran, Brasil. Revista Brasileira de Agroecologia, v. 2, n. 1, p. 196-199, fev. 2007.

IKUTA, A. R. Y.; BARROS, I. B. I., Estudo de caso: Perspectivas de sustentabilidade de uma comunidade indígena Mbyá Guarani no Rio Grande do Sul, Mata Atlântica, Brasil. Revista Brasileira de Agroecologia, v. 1, n. 1, p. 1187-1190, nov. 2006.

KAIABI, T. et al. Resgate cultural e manejo da agrobiodiversidade em roças indígenas: experiências Kaiabi e Yudja no Parque Indígena do Xingu, MT. Agriculturas, v. 1, n. 1, p. 6-8, nov. 2004.

KAYAPÓ, Kaikware; KAYAPÓ, Bengoti; JEROZOLIMSKI, Adriano; NEVES, Ramon de Paula. Fortalecendo a cadeia produtiva da Castanha-da-Amazônia (Bertholletia excelsa) em comunidades Kayapó do Sul do Pará. Cadernos de Agroecologia, Vol 8, No. 2, Nov 2013.

KRIEGEL, R. K.; AZEVEDO, E. O.; SILVA, F. F. Relação do Grupo Indígena Guarani Mybiá com o meio ambiente: alicerces da agroecologia. Revista em Agronegócios e Meio Ambiente, v. 7, n. 1, p. 211-226, abr. 2014.

LIMA, A. S. T.; XAVIER, T. F.; SAPARA, R. T. Difusão de praticas agroecologicas em comunidade indígena. Cadernos de Agroecologia, v.10, n. 3, p. 1-5, 2015.

LOPES, R. S.; BEZERRA, T. S. Assistência técnica e extensão rural - ATER aos povos indígenas: relatos de uma experiência com as comunidades Tremembé de Acaraú. Cadernos de Agroecologia, v. 6, n. 2, p. 1-5, dez. 2011.

LÓPEZ, F. M. A Contribuição sociocultural do Colégio Estadual Benedito Rokag, Terra Indigena Kaingang Apucaraninha (Tamarana, PR). Araras: Universidade Federal de São Carlos, Dissertação (Mestrado em Agroecologia e Desenvolvimento Rural), 2016.

MACIEL, V. R. Restauração florestal em áreas de pastagem na Terra Indígena Laranjinha/PR. Araras: Universidade Federal de São Carlos, Dissertação (Mestrado em Agroecologia e Desenvolvimento Rural), 2012.

MARQUES, C. T dos S.; GAMA, E.V. S.; CARVALHO, A. J. A.; SILVA, F.; FRIAS, M. T. Influência lunar nas práticas agrícolas da Aldeia Indígena Tupinambá de Serrado Padeiro, Buerarema - BA. Revista Brasileira de Agroecologia, vol.2, n.2, out. 2007.

MARQUES, C. T. dos S.; GAMA, E. V. S.; CARVALHO, A. J. A., A agricultura do Povo Tupinambá de Serra do Padeiro, Buerarema - Bahia. Revista Brasileira de Agroecologia, vol. 4, n. 2, nov. 2009. 
MARQUES, R. R. et al. Educação na Aldeia Te'yikue, em Caarapó, Mato Grosso do Sul - a conquista do curso de Técnico em Agroecologia. Cadernos de Agroecologia, v. 7, n. 2, p. 1-5, dez. 2012.

MELO, A. V.; SANT'ANA, G. R. Fortalecendo processos agroflorestais entre os Terena: Pronatec-IFMS na Terra Indígena Cachoeirinha. Cadernos de Agroecologia, v. 9, n. 4, p. 1-8, nov. 2014.

MODERCIN, I. F.; CASTRO, M. S.; BANDEIRA, F.P.S.F. Manejo sustentável de abelhas sem ferrão no Território Indígena Pankararé, Raso da Catarina, Bahia. Revista Brasileira de Agroecologia, v. 2, n. 2, p. 1277-1281, out. 2007.

MORAES, C. et al. Povos indígenas e agrobiodiversidade: Identificação dos participantes e variedades agrícolas da IX Feira Krahô de Sementes Tradicionais. Cadernos de Agroecologia, v. 9, n. 3, p. 1-5, 2014.

NASCIMENTO, J. et al. Educação Ambiental na Aldeia Pataxó Barra Velha: A inserção da agroecologia no ensino. Revista Brasileira de Agroecologia, v. 2, n. 2, p. 529-533, out. 2007.

NEVES, R.A.D; MORAIS, R.F., Sistema agroflorestal em Savana Parque Arbóreo no município de Amajari, RR. Cadernos de Agroecologia, vol. 10, n. 3, p. 1-5, 2015.

NODA, S. N.; MARTINS, A. L. U.; Noda, H.; SILVA, A. I. C.; BRAGA, M. D. S. Paisagens e etnoconhecimentos na agricultura Ticuna e Cocama no alto rio Solimões, Amazonas. Boletim do Museu Paraense Emílio Goeldi. Ciências Humanas, Belém, v. 7, n. 2, p. 397-416, maio-ago. 2012.

NODA, S. N.; NODA, H.; BROCKI, E. Percepção e utilização da flora nas culturas Ticuna e Cocama na microrregião do alto Solimões, estado do Amazonas, Brasil. In: MOREIRA, Fátima M. S.; SIQUEIRA, José O.; BRUSSAARD, Lijbeert. Biodiversidade do solo em ecossistemas brasileiros. Lavras: UFLA, 2008. p. 43-65. NOELLI, F.S. (org.) Bibliografia Kaingang: referências sobre um povo Jê do sul do Brasil. Londrina: Eduel, 1998.

NORDER, L. A. C.; RODRIGUES, D. C. A. Implementação de sistema agroflorestal demonstrativo na Terra Indígena Kaingang Apucaraninha, Londrina/PR. Cadernos de Agroecologia, v. 2, n. 2, p. 587-589, out. 2007.

NORDER, L.A., LAMINE, C., BELLON, S., BRANDENBURG, A., Agroecologia: polissemia, pluralismo e controvérsias. Revista Ambiente e Sociedade, vol. 19, n.3, p. $1-20$.

NUNES, F. O. et al. Criação e manejo sustentável de abelhas sem ferrão no Território Indígena Pankararé (TIP), Raso da Catarina, Bahia, Brasil. Revista Brasileira de Agroecologia, v. 4, n. 2, p. 3123-3127, nov. 2009.

OLIVEIRA, E. S. de. et al. Invertendo papéis e fortalecendo as práticas agroecológicas no campo: trocas de experiências entre agricultores familiares e alunos do IFAM Campus Tabatinga. Cadernos de Agroecologia, v. 10, n. 3, p. 1-5, 2015. 
OLIVEIRA, Elenilson Silva de et al. Oficinas de troca de saberes no cultivo da mandioca por agricultores familiares indígenas de Belém do Solimões, Tabatinga-AM. Cadernos de Agroecologia, v. 10, n. 3, maio 2016.

PINHO, R. C. Quintais agroflorestais indígenas em área de savana (lavrado) na Terra Indígena Araçá, Roraima. Manaus: Instituto Nacional de Pesquisa da Amazônia, Universidade Federal do Amazonas. Dissertação de Mestrado em Ciências Florestais Tropicais. 2008.

PINTO, I.C. et al. Agrofloresta: sustentabilidade na Comunidade Indígena Assunção do Içana (Alto Rio Negro, AM). Revista Brasileira de Agroecologia, vol. 4, n. 2, p. 546549, nov. 2009.

PINTO, J. G.; GARAVELlO, M. E. P. E. Transformação (agri)cultural ou etnossustentabilidade: relato de uma aldeia Bororo. Agroecologia e Desenvolvimento Rural Sustentável, Porto Alegre, v.3, n.2, abr./jun. 2002.

PIOVEZAN, U.; CAMPOLIN, A. I.; FEIDEN, A. Diagnóstico parcial do potencial para a produção agroecológica na terra indígena Guató - Ilha Ínsua, MS. Revista Brasileira de Agroecologia, v. 2, n. 2, p. 54-57, out. 2007.

PÖRSCH, J. et al. Saberes da natureza e conhecimento etnobotânico indígena: o caso da comunidade Kaingang da Terra Indígena do Guarita. Cadernos de Agroecologia, v. 8, n. 2, p. 1-9, nov. 2013.

QUEIROZ, J. A. L.; SANTOS, J. de A dos; NÓBREGA, A. P. Intercâmbio de Conhecimento para Manejo de Mínimo Impacto de Açaizal Nativo em Aldeias Indígenas na BR-156 no Estado do Amapá (Projeto FRUTIINDO). Cadernos de Agroecologia, v. 10, n. 3, p. 1-6, 2015.

RAMOS, P. R.; JANUARIO, E.; BAMPI, A. C. O manejo do solo entre os Tapirapé da aldeia Tapi'itãwa na região do médio norte Araguaia- Estado de Mato Grosso. Cadernos de Agroecologia - ISSN 2236-7934, vol 8, n. 2, Nov 2013.

ROCHA, Juliana Coura. Avaliação de leguminosas lenhosas para adubação verde em roças da terra indígena araçá, Roraima. Manaus: Instituto Nacional de Pesquisa da Amazônia (INPA), Dissertação de Mestrado em Agricultura no Trópico Úmido. 2010.

RODRIGUES, D. C. A. Concepções e práticas agroflorestais na Terra Indígena Kaigang Apucaraninha (Paraná). Londrina: Universidade Estadual de Londrina, Dissertação de Mestrado em Ciências Sociais. 2008.

RODRIGUES, R. A.; NISHIKAWA, D. L. A condição sócio-ambiental na área indígena "Índia Vanuíre", município de Arco-Íris, e as possibilidades de adequação agroecológica e de recuperação florestal. Periódico Eletrônico Fórum Ambiental da Alta Paulista, Tupã, v. 3, p. 158-170, 2007.

SANTOS, N. R. dos; DIAS, T. A. B. Roças indígenas krahô: levantamento preliminar das interações ecológicas e sócio-culturais na aldeia Pedra Branca/TO. In. Congresso 
Brasileiro de Recursos Genéticos, 3, 2014, Santos. Anais... Brasília, DF: Sociedade Brasileira de Recursos Genéticos, 2014. Resumo. 630.

SARDO, P.M., FIGUEIREDO, R.A., A construção do campo da Agroecologia e sua relação com o desenvolvimento rural. Revista Internacional Interdisciplinar Interthesis, vol. 12, n. 1, p. 337-360, 2015

SILVA, A. L. da. Curso de implantação de horta agroecológica na Aldeia Guató, no Município de Corumbá, MS. Cadernos de Agroecologia, v. 5, n. 1, p. 1-5, 2010.

SILVA, D. M. P. et al. Variação espacial da estabilidade dos agregados e estoque de carbono em área de terra preta arqueológica sob cultivo de cacau. Revista Brasileira de Agroecologia, v. 11, n. 3, p. 179-187, set. 2016.

SILVA, L. F.; LOURENÇO, F. de S.; XISTO, G. J. Avaliação participativa de Indicadores de Sustentabilidade no manejo de agroecossistemas de guaraná (Paullinia cupana Kunth) em três propriedades familiares das comunidades Nova União e Vida Feliz da área indígena Sateré Mawé no Andirá-Barreirinha/AM. Cadernos de Agroecologia, v. 6, n. 2, p. 1-6, dez. 2011.

SIQUEIRA, C. de S. et al. Diagnóstico de nascentes em Área Indígena (Diagnosis of East in Indigenous Area). Revista Brasileira de Agroecologia, v. 2, n. 2, p. 1458-1460, out. 2007.

SMITH, M.; GUIMARÃES, M. A. Gestão ambiental e territorial de terras Indígenas: reflexões sobre a construção de uma nova política indigenista. In: Encontro da Associação Nacional de Pós-Graduação e Pesquisa em Ambiente e Sociedade, 5., 2010. Anais... Florianópolis: ANPPAS, 2010.

SOARES, M. de A. Contribuições para reflexão de uma ATER Indígena: fortalecimento do sistema cultural de coletivos Guarani no Rio Grande do Sul. Cadernos de Agroecologia, v. 8, n. 2, p. 1-5, nov. 2013.

SOUZA, O. C.; SALVADOR, M. N. R. Enriquecimento de quintais e a experiência da prática agroecológica dentre os Terena da Aldeia Lalima: resultados iniciais do Projeto GATI. Cadernos de Agroecologia, v. 9, n. 4, p. 1-5, nov. 2014.

TEIXEIRA, C. A. Análise do programa de aquisição de alimentos (PAA) no Território Indígena Caramuru Catarina Paraguaçu no Município de Pau Brasil (BA). 2016. 122 p. Dissertação (Mestrado em Agroecologia e Desenvolvimento Rural) Universidade Federal de São Carlos, Araras.

VASCONCELOS, S. Agroecossistemas, como estratégia para práticas sustentáveis em uma propriedade no Território Kaimbé, Semi-Árido Baiano. Revista Brasileira de Agroecologia, v. 4, n. 2, p. 2085-2088, nov. 2009. 
VASCONCELOS, S.; ALARDO SOUTO, L.; ALVES, A. A permacultura como ferramenta de socialização na comunidade indígena Kaimbé, semi-árido baiano - um relato de caso. Cadernos de Agroecologia, v. 6, n. 2, p. 1-5, dez. 2011.

VIANA, I.M. Fortalecimento dos povos tradicionais a partir de princípios agroecológicos. Cadernos de Agroecologia, v. 10, n. 3, maio 2016.

WEISS, D. et al., Difusão da agroecologia na Comunidade Indígena de Terra do Guarita. Jornada de Extensão, 17., 2016, Ijuí. Relatório técnico-científico. Ijuí: Unijuí, 2016. 6 p.

WOLFF, L. F. Sistemas agroforestales apícolas: instrumento para la sustentabilidad de la agricultura familiar, assentado de la reforma agraria, afrodescendientes quilombolas e indígenas guaraníes. Córdoba: Universidad de Córdoba, Tese de Doutorado em Recursos Naturales; Instituto de Sociologia y Estudios Campesinos, 2014

WOLFF, L. F.; SCHWENGBER, J. E.; GOMES, G. C.; GOMES, J. C. C. Estratégias de organização e gênero em sistemas apícolas. Cadernos de Agroecologia, v. 10, n. 3, out. 2015 . 